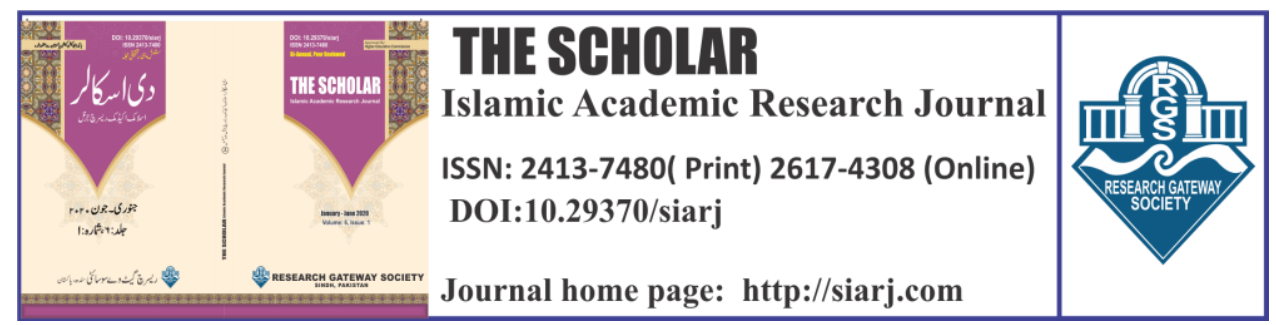

$$
\text { دراسة المؤلفات العربية المحديدة حول المعاهدات النبوية صلى الله عليه وسلم }
$$

\title{
ARABIC-A STUDY OF ARABIC BOOKS OF MORDER ERA ON THE PROPHETIC TREATIES AND COVENANTS
}

\author{
1- Nasrullah Khan Muzaffar \\ PhD Scholar, Allama Iqbal Open University, \\ Islamabad, Pakistan \\ Email : nasrullah0332@gmail.com \\ ORCID ID: \\ https://orcid.org/0000-0002-8543-1920
}

\begin{abstract}
2. Dr. Shah Moeen ud Din Hashmi
Chairman, Department of Seerat Studies, Faculty of Arabic and Islamic Studies, Allama Iqbal Open University, Islamabad, Pakistan Email: moeen.uddin@aiou.edu.pk
\end{abstract}

\section{ORCID |D:}

https://orcid.org/0000-0003-4451-6650

To cite this article:

Nasrullah Khan Muzaffar, Shah Moeen ud Din Hashmi. "A STUDY OF ARABIC BOOKS OF MORDER ERA ON THE PROPHETIC TREATIES AND COVENANTS" The Scholar-Islamic Academic Research Journal 6, No. 1 (May 31, 2020): 18-50.

To link to this article: https://doi.org/10.29370/siarj/issue10ar7

\begin{tabular}{|c|c|}
\hline Journal & $\begin{array}{l}\text { The Scholar Islamic Academic Research Journal } \\
\text { Vol } 6 \text {. No } 1 \text { || Janurary -June } 2020 \text { || P 01-16 }\end{array}$ \\
\hline Publisher & Research Gateway Society \\
\hline DOI: & 10.29370/siarj/issue10ar7 \\
\hline URL: & https://doi.org/10.29370/siarj/issue10ar7 \\
\hline License: & Copyright c 2017 NC-SA 4.0 \\
\hline Journal homepage & www.siarj.com \\
\hline Published online: & 2019-05-31 \\
\hline
\end{tabular}

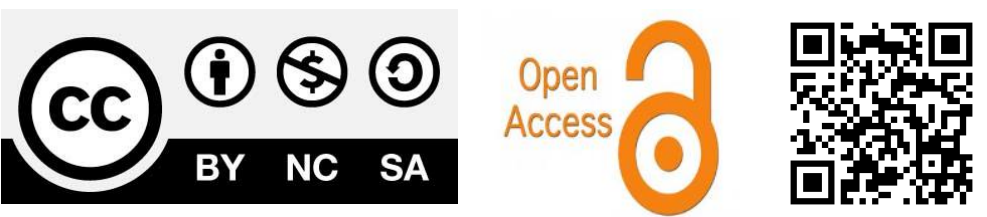




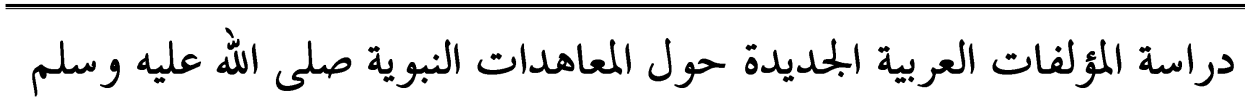

\section{ARABIC-A STUDY OF ARABIC BOOKS OF MORDER ERA ON THE PROPHETIC TREATIES AND COVENANTS}

Nasrullah Khan Muzaffar, Shah Moeen ud Din Hashmi

\section{ABSTRACT:}

This brief research paper consists of an analytical study of the modern books compiled on the topic of treaties and covenants of The Holy Prophet (Peace Be Upon Him) with other tribes and nations. In this regard, in the modern literature of Arabic, four authors are very prominent and famous, they are: Muhammmad Abd ul Munim Khan, Dr Muhammad Hameedullah, Ali bin Husain Ali Al ahmadi and Awon alshreef Qasim. Their worthy books and compilations are so comprehensive and reasonable on the above mentioned topic. The topic of Holy Prophet's covenants has too much importance because it shows His political approach as a successful ruler. So, a research analysis will be presented here about the said books and their authors as under:

\section{Brief introduction of the authors}

. 2. Main contents of the books.

3. Special style and characteristics of the books.

4. Some specimens from the books.

This topic is as important today as it was years ago. Students of comparative literature essentially need to study the divine religions, their 
spread, characteristics, and the political approach of the leaders of these religions. So, the letters of the Prophet and his political documents caught the attention of researchers of all generations and generations.

KEYWORDS: Tribes, Constitution, Prophet, books of modern era.

الكلمات المفتاحية: المكاتيب ، الأسلوب، المعاهدات، لنبوية، المؤلفات العربية الملديدة المدخل:

يطلق لفظ "المكاتيب" على المراسلات و الرسالات عادية ولكن في جميع الكتب التي دونت قديماً وحديثاً حول موضوع مكاتيب البي ذكرت فيها رسائل البي صلى الله عليه و سلم إلى ملوكى الدول المختلفة وعمائد القبائل المتنوعة، و الوثائق الحكومية و السياسية و العهود بين الأقوام والملل.كل شئي يكتب فهومكتوب فثبت من ذلك أن العهود و المعاهدات كتبت بأمر النبي صلى الله عليه و سلم فدخلت في المكاتيب. " العهد" لفظ مشترك يقع في اللغة على ستة معان:

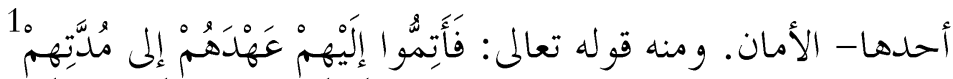

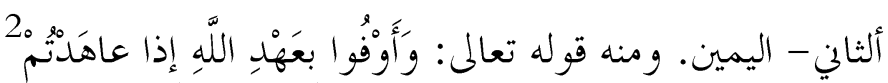
الثالث- الحفاظ. ومنه قوله صلّى الله عليه وسلّم: 》حسن العهد من الإيمان《) .

${ }^{1}$ Al-Quran, 9:2.

${ }^{2}$ Al-Quran.16:91

${ }^{3}$ Abu Bakar Ahmad al Husain bin Ali Al Behaqi, Shuab al Iman, 1st ed., vol. 11 (Riyadh, Saudia: Maktabat ul Rushd Lil nashr wal tauzi, 2003), 378. 
الر ابع- الذّمّة. ومنه قوله صلّى الله عليه وسلّم الا يقتل مسلم بكافر ولا ذو عهد في الخنامس- الزّمان. ومنه قولهم: 》كان ذلك على عهد فلان) .(كما انشق القمرعلى 5 عهد رسول الله صلى الله عليه وسلم) السادس - الوصية. ومنه قوله تعالى وَكَقَدْ عَهِدْنا إلِى آدَمَ مِنْ قَبْلُ فَنَسِيَ وهو المر اد هنا.قال الجوهريّ: ومنه اشتقّ "العهد" الذي يكتب للولاة 7

فلذلك توجد في كتب مكاتيب البي صلى الله عليه وسلم " عهود البي ومعاهداته صلى الله عليه وسلم. العديدةالمتنوعة " كمثل العهد الدستوري وعهد الصلح وعهد بتديد الحليفية وعهود الأمان والإقطاع وغير ذلك.

ولكن سُمّيت هذه الكتب بالمكاتيب والمكتوبات والرسالات و الرسائل للبي صلى الله عليه وسلم تغليباً وفيهن معاهدات البي أيضاً.فأستقي المادة العلمية من هذه المصادر و المر اجع لبحثي المتواضع حول موضوع معاهدات الببي. فأنا أتعرض إلى المؤلفات العربية الحديثة حول هذا الموضوع وأيضا سأتعرف خلال هذا البحث إلى المؤلفات التا ليفات ومؤلفيها و كذلك سأبحث فيه عن أساليبهم ومناهجهم إن شاء الله عز و جل. (1). الناليف الأول : رسالات نبويه عليه التحية محمدعبدالمنعم خحان

${ }^{4}$ Al Nisae Ahmad bin Shoaib, Sunan Al Nisae, vol. 8 (Beirut: Mu'assiah al-Risālah, 2001), 27.

${ }^{5}$ Abu Daud, Sulaiman bin Daud bin Jarud Al Tialsi, Musnad Abi Daud Al Tialsi, 1st ed., vol. 1 (Egypt: Dar Hijr, Egypt), 224.

${ }^{6}$ Al-Quran.20:115

${ }^{7}$ Al-Kalkashandy, Ahmad bin Ali bin Ahmad Alfazari, Subhul A'asha Fi Sina'atul Insha, vol. 9 (Beirut: Dar ul Kutubil Elmia, n.d.), 364 . 
هناكى رياسة في الهند تسمي ب " تونك" ولها نواب أي رئيس وكان هو جد لممد

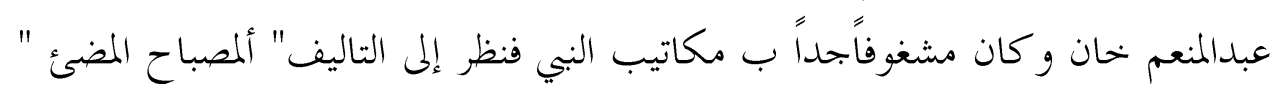

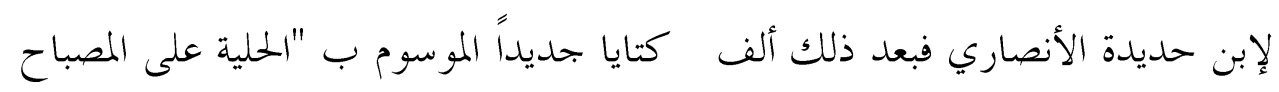
المضيئة". ذكر في "المصباح المضئ" واحد وأربعون مكتوبا وزاد صاحب"الحلية" عليها ثلاثة عشر مكتوبا فبلغ أربعة وخمسين. مكتوبا، وبعد صاحب الحلية حصلت السعادة

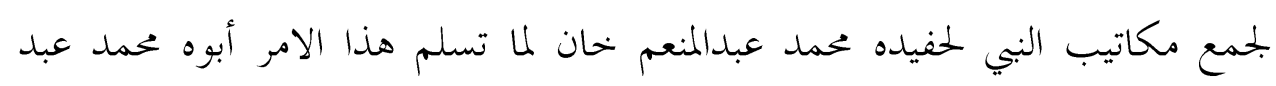
الرحيم خان ( الركن البيتي لديوان الرياسة " تونك " في الهند) أن يترجم كتاب جده النمان بالأردية فبدء الترجمة وزاد عليه مكاتيب أخري من المصادر المختلفة من كتب الحديث 8

ورتب كتاباً جديداً بالعربية بعنوان التاريخي " رسالات نبوية عليه التحية " فجمع فيه مائة و ستة وعشرين مكتوبا و بإختلاف الرو ايات بلغ عددالمكاتيب مائة وتسعة وثلاثين. وقد ذكر رفيقه الخاص مكتوبا الحافظ محمد عبيدالله لهذا الكتاب أسماء عديدة بمناسبة

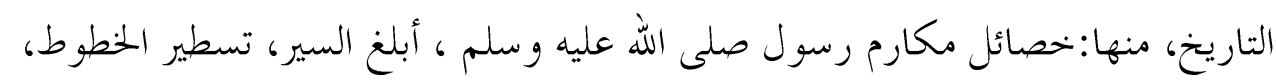
ترجمة خطوط نبوي، أخبار وأحاديث، أخلاق الشارع وتقويم المذاهب. طبع هذا الكتاب في عام ب ب ا هـ بمطبع دلي برنتنگ بريس، دهلي.

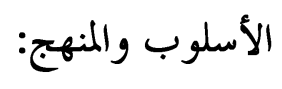

1) ألف المؤلف كتابا باللغة العربية ومعه ترجم إلى اللغة العربية. 2) شرح المقامات الصعبة والكلمات المغلقة في الحو اشي.

${ }^{8}$ Muhammad Abdul Munim Khan, Risalat e Nabvia (Delhi: Delhi Printing Press, 1336H), 5. 
3) أسلوبه الفريد الذي لايوجد في كتب أخري حول هذا الموضوع أنه رتب المكاتيب على طراز الأبواب الفقهية واستبط المسائل ما تتعلق هما ودرج بعد بردي فهرس الكتاب، فهرس الأبو اب الفقهية وكتب أرقام الصفحات حسب المسائل المختلفة لسهولة القارئين. 4) وقد تلقي المؤلفون لهذا الكتاب بالقبول ، و كل و احد من المؤلفين بعده قد أخذا.

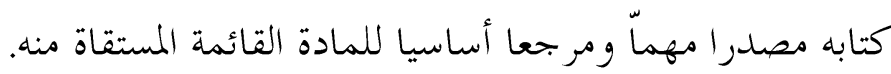
5) أن كتابه كتاب جامع من جميع الكتب التي دُوّنت في هذا البحال باللغة العربية أو الأردية وضخيم جد الكثرة المكاتيب النبوية فيه. 6) ذكر المؤلف في أول الكتابه1 مكتوبا التي رويت من غير لفظ ولكن لاتوجد الكلمات كلها في مصدر واحد وجمع في كتابه وبا و وبإختلاف الروايات وبا مكتوبا للبي صلى الله عليه وسلم وفي آخر الكتاب ضم إليه فهرس

$$
\text { الأغلاط في الأردية والعر بية. }
$$

7) قد رتب علي ترتيب الأبواب الفقهية وهي كما يلي: كتاب الطهارة، كتاب

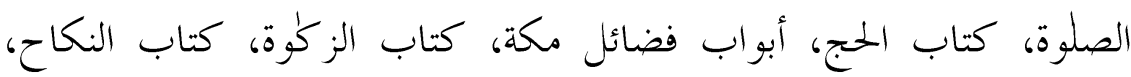
كتاب البيوع، كتاب الحضر والإباحة، كتاب الأشربة، كتاب الجهاد والسير،

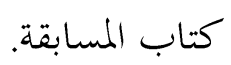

(r) التاليف الثاني :بحموعة الوثائق السياسية في عهد البي وفي عهد المخلافة الراشدة :للدكتور محمد حميد الله: نبذة مختصرة عن حياة الدكتورمحمد حميد الله

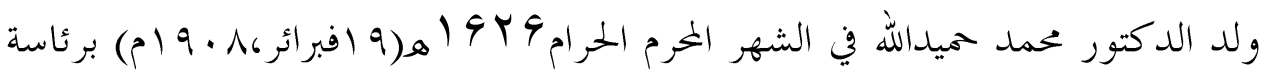

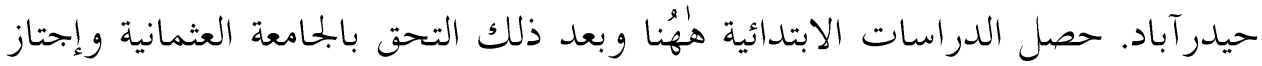


دراسة المؤلفات العربية الجديدة حول المعاهدات النبوية صلى الله عليه وسلم

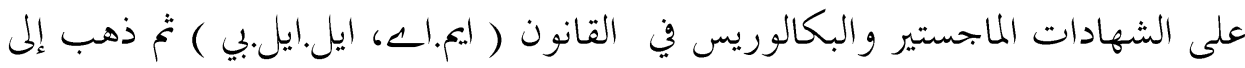

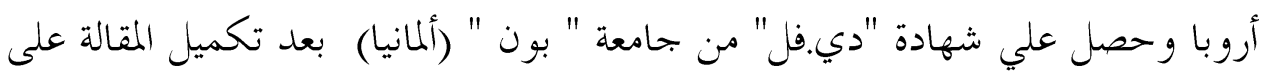

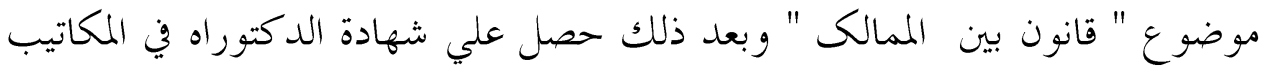

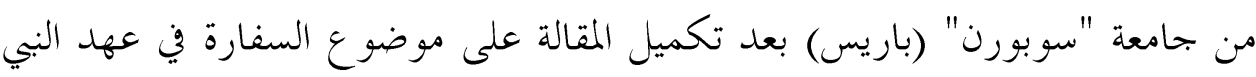
صلى الله عليه وسلم و الخلافة الراشدة.

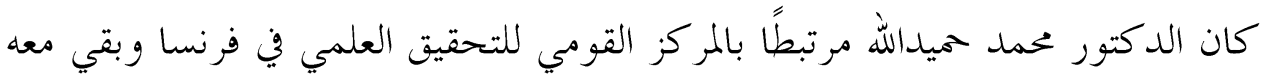
عشرون عاما وفي أثناء ذلك كان أستاذا في الجامعات العديدة في ألمانيا وفرنسا.

مؤلفاته:

قد ألف الدكتور المذكور كتبًا كثيرًا ومقالات عديدة حول موضوع السيرة النبوية صلى الله عليه وسلم في اللغات الأروبية. وقد تلقي الناس كتبه بالقبول والتقدير واشتهرت كتبه وانتشرت في ارجاء التعالم كلها، منها : مؤلفه بالإنخليزية " محمد رسول الله " وترجمته للقرآن باللغة الفرنسية وكذلك كتابه حول موضوع السيرة النبوية مقبول جداً. و تاليفه مهم جدا على موضوع المكاتيب والمعاهدات باللغة العربية هو "بحموعة الوثائق

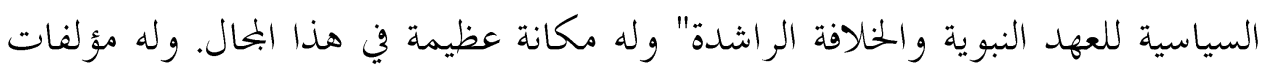

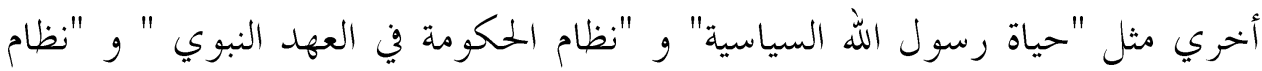

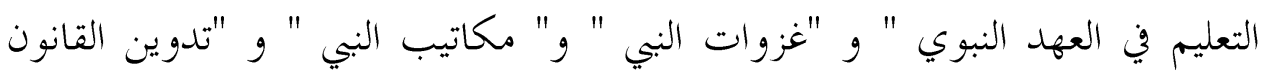

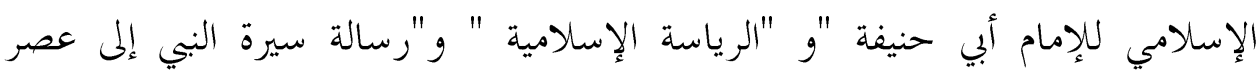
الحاضر " و "العلاقات بين العرب والأحابيش" و"القو اعد للعلاقات بين الممالك و الدُّول و أمثلتيه ". 
دراسة المؤلفات العربية المحديدة حول المعاهدات النبوية صلى الله عليه وسلم

وقد كتب مقالات كثيرة و كنبا عديدة على السيرة النبوية صلى الله عليه وسلم في اللغات الأوربية المختلفة. وقد طبعت ترجمته للقرآن الكريم وبحلدان حول موضوع السيرة النبوية باللغة الفرنسية عدة مرات.

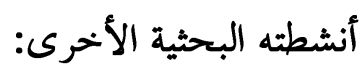

أحخذ مخطوطة من المكتبة "برلن " لصحيفة همام بن منبه وطبعه حسب طرق البحث

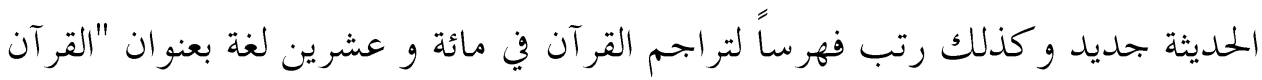
في كل لسان". وأيضا رقم نموذجا لتراجم سورة الفاتحة وكذلك رتب القائمة الإشارية ل "الجامع الصحيح للإمام بخاري".

وألقي المحاضرات في الجلامعة الاسلامية هاولبور باكستان من ^ مارس إلى ·ب مارس

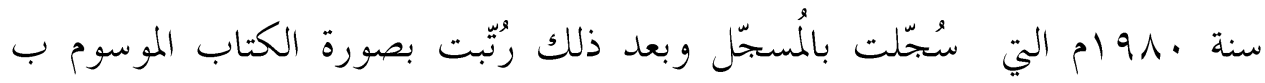
"خطبات هماولبور" الذي هو مخزن أفكاره العلمية و البحثية.

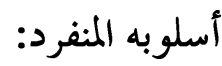
أسلوبه المنفرد في التحرير والخطاب أنه لا يهتجم علي مخالفيه ولا يجادهم إلا بالتي هي أحسن مثل المناظرين بل يقدم موقفه بعد البحث التام والتفحُّص في المصادر الأصلية القديمة والحديثة فمن ذلك أسلوبه علمي الذي هو أسلوب البحتهدين، و مطالعته وخبرته العلمية وسيع جدا وله يد طولي' في بحث المصادر الأصلية والمراجع الثانوية. في تاليفاته توجد كثرة المراجع في كل رواية وله تفردات ايضاً في المسائل الإجتهادية كمثل إمامة المرأة في الصلوةة وغير ذلك. وفاته:

${ }^{9}$ Dr. Muhammad Hameedullah, Khutbat e Bahawalpur (Introduction by Abdul Qayyum Qureshi (Islamabad: Idara Tahqiqat e Islami, n.d.), 14-15. 
دراسة المؤلفات العربية المحديدة حول المعاهدات النبوية صلى الله عليه وسلم

IV توفي هذا البطل العظيم، المقق، المدقق ،الداعي، المبلغ للدين الحنيف في ديار الغرب

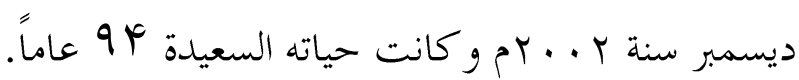

الأسلوب والمنهج بلمموعة الوثائق السياسية للعهد النبوي والخلافة الراشدة: أول من صنف على موضوع مكاتيب البي صلى الله عليه وسلم ومعاهداته بعد محمد عبد المنعم خان في الهند هو الدكتور محمد حميد الله ، هو رتب مقالته البحثية للدكتوراه

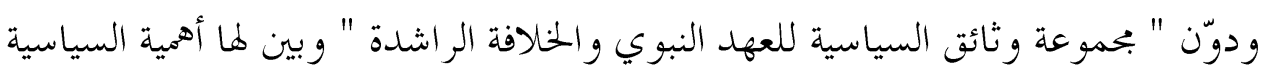

و التاريخية و كانت هذه المقالة باللغة الفرنسية وطبعت من باريس تحت العنوان:

\section{Documents Surla Diplomate Muslmans}

و بعدئذٍ قد حققها مزيداً وأضاف إليها وترجمها إلى اللغة العربية وسماها "بحموعة الوثائق السياسية للعهد النبوي والخهلافة الراشدة" وطبعها من مصر في سنة هسو ام. ونالت هذه المقالة مكانة فخيمة وشهرة عظيمة. وقد إختار أسلوباً رائعاً في هذا الكتاب مع مزية خاصة أن المصنف الفاضل جمع فيه مر اجع ومصادر كثيرة لكل مكتوب.

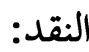

وقد قام محمد عبد الشهيد نعماني بنقد أسلوبه قائلاً أن سعي الدكتور هذا سعي مشكور ولكن لم يهتم صحة المكاتيب لكثرة المراجع والمصادر بكثرة المصادر والمراجع ويذكر إختلاف النسخ بالالتزام ولايبين لماذا هذا الاختلاف، وما هو أصح المتون وفي أكثر المقامات درج أصل المنن لطبقات ابن سعد واكتفي على ذلك أن في كتب أخري اختلاف في المتن . وبسبب ذلك يكون المتن الغلط .متزلة المنن الصحيح، ولو توجه إلى هذه الجهة لكانت في "بحموعة الوثائق السياسية للعهد النبوي والخافة الراشدة" مآخذ

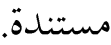
و لم يعتن معارضة كتب غرائب الحديث الاا لزخشري في المواضع المحدودة. و كذلك استفاد قليلاًمن كتب لغات الحديث إلامن كتابين فتط أعني من"النهاية في غريب 
دراسة المؤلفات العربية المحديدة حول المعاهدات النبوية صلى الله عليه وسلم

الحديث والأثر "لابن الأثير ومن "الفائق في غريب الحديث" للزخششري في مواضع ولو معدودة، ولوراجع إلى كتب غريب المحيث وزاد الكتاب ثنة و صحة.

وقد ضم في آخرالكتاب ضميمةً تشرح المقامات الصعبة المذكورة في المكاتيب على

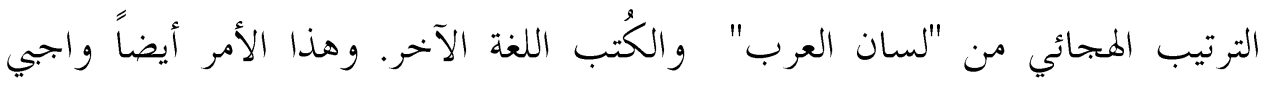
سطحي ليس بمهم خاص. ولاينبغي لنا أن ننقد على الدكتور وهو محترم عندنا من كل جهة وطبعه الساذج وشغفه للدين ودركه في العلوم لنا مشعل الطريق ولكن لا بد لنا

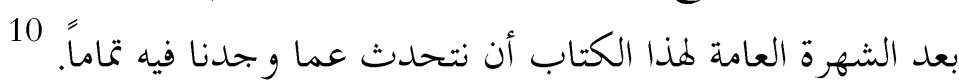
ترتيب"بحموعة الوثائق السياسية للعهد النبوي والخلافة الراشدة"

قد قسم الدكتورمحمد حميدالله معاهدات النبوي في هذا الكتاب المذكور إلى قسمين: القسم الأول: العهد النبوي صلى الله عليه وسلم قبل الهجرة: ذكرت فيه مكتوب النبي صلى الله عليه وسلم للنجاشي لحسن السلوكى ممهاجري مكة المكرمة والإقطاع للداريين ومقاطعة قريش وبيعة العقبة الأولي والثانية والثالثة ومكتوب

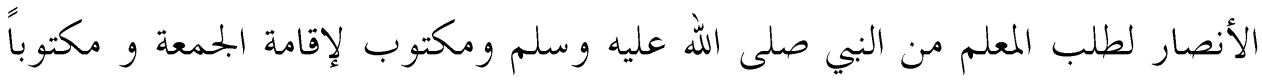
لسر اقة بن مالك المدلجي على مناسبة الهجرة. القسم الثانى: العهد النبوي صلى الله عليه وسلم بعد الهجرة ذكر فيه معاهدات النبي صلى الله عليه وسلم كما يأتي: كتابه صلى الله عليه وسلم بين المهاجرين والأنصار واليهود وهوالدستور البلدية

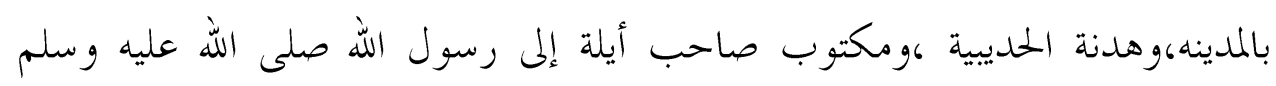
ومعاهدته مع أهل أيلة، ومعاهدتاه مع أهل جرباء وأذرح ، ومعاهدته مع أهل مقنا،

${ }^{10}$ Muhammad Abdul Shaheed, Farameen e Nabvi (Karachi19: Al Raheem Academy Liaqat Abad, n.d.), 24. 
دراسة المؤلفات العربية الجمديدة حول المعاهدات النبوية صلى الله عليه وسلم

والمعاهدة مع بني ثعلبة من غسان، قبيلة حدس من لخم، زياد بن جهور اللخمى، الإقطاع للداريين وهم من لخم، ومكاتبته مع أهل هجر، إلى أسيبخت عامل بحرين لكسرى، أهل عمان والبحرين، إلى الهلال صاحب البحرين، والمكاتبة مع هوذة بن علي (شيخ اليمامة)، إلى ثمامة بن أثنال رئيس اليمامة ، ومعاهدته مع نصاري بخران،سنختان لمكتوب النبي إلى بحران، كتابه إلى الولاة ، تعليمات إلى معاذ بن جبل، إلى ملوك رلى اليمن،جواب البي صلى الله عليه و سلم لكتاهم إلى الحارث بن عبد كلال وغيره، و كتابه لعمرو بن حزم(عامله إلى اليمن)، و كتابه إلى أهل اليمن،عهده لقيس الممداني على قومه، لمالك بن النمط وقومه من همدان، مهري بن الابيض، مكاتبة أكثم بن صيفي مع رسول

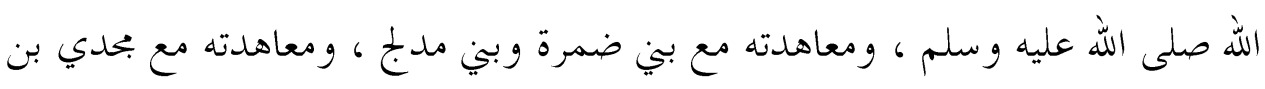
عمرو سيد بي ضمر ،و كتابه إلى عامة المسلمين في ثقيف. تقابل الدكتور محمد حميدالله على موضوع معاهدات البي صلى الله عليه وسلم مصادر

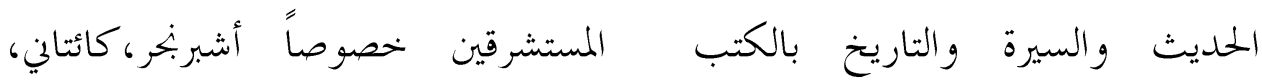
سبريبر،ويلهاؤزن، فنسك. يبحث الدكتور محمد حميد الله عن المصادر والمراجع قبل متون المعاهدات النبي صلى الله عليه وسلم أولا تم يذكر جميع المصادر.ويجعل علامة الاستفهام أثناء المتون وفي بعض الاماكن يصحح في القوسين حتي الإمكان. ويستخدم رموز الاختصارات للمصادر

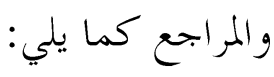

رموز الاختصارات للمصادر المستخدمة في" بحموعة الوثائق السياسية للعهد النبوي

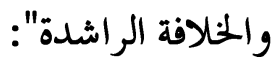

با:سيرة ابن اسحاق.ب: أسد الغابة لابن الأثير، بح: الإصابة لابن حجر، بحز: جوامع السيرة لابن حزم، بحن:مسند أحمد بن حنبل، بد: سنن أبي داؤد، بس: طبقات ابن

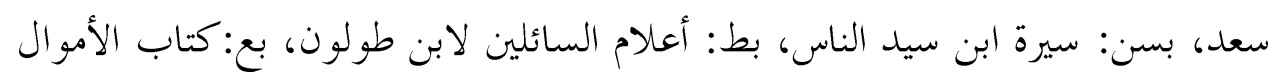
لأبي عبيد، بعب: الاستيعاب لابن عبدالبر، بعح: فتوح مصر لابن عبدالحكم، بعر : ابن 
عبد ربه، بق: زاد المعاد لابن القيم، بك: البداية والنهاية لابن كثير، بلا: فتوح البلدان

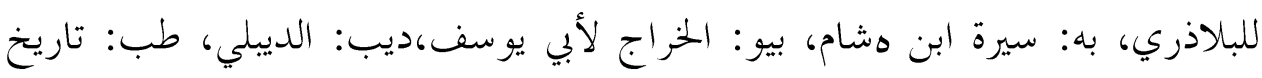

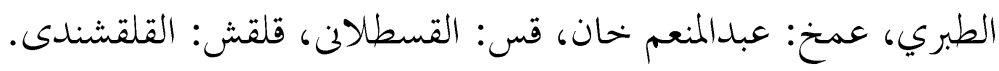

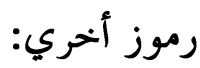
الف: طرف الوجه من ورقة المخطوطة،ب: طرف الظهر من ورقة المخطوطة،ج: الجزء

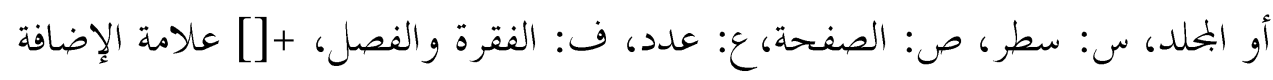

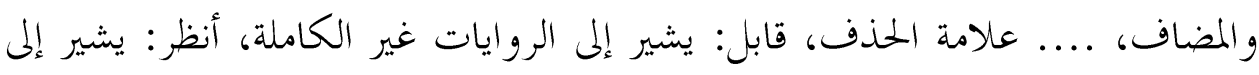

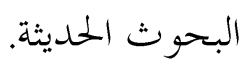
كثرة المصادر والمر اجع في بحموعة الوثائق السياسية تدل على أن الدكتور محمد حميد الله

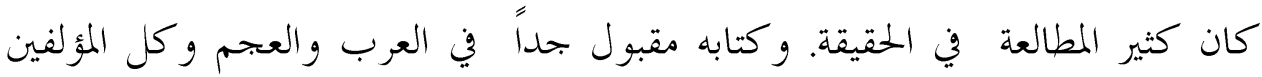

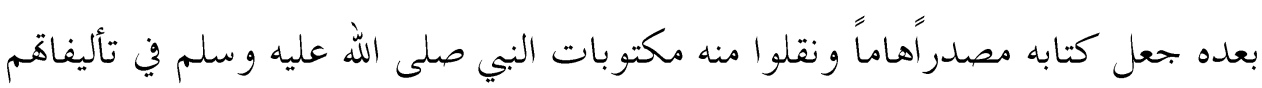

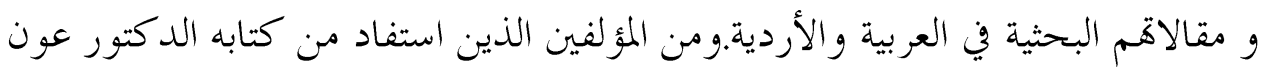

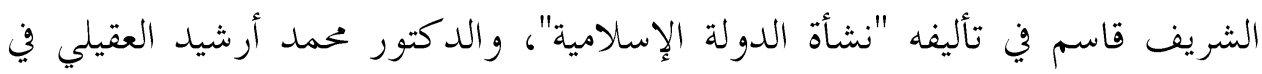

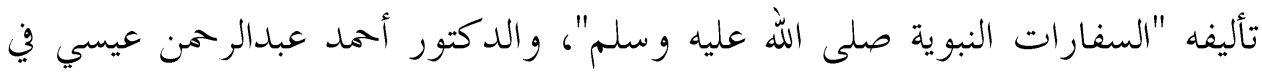

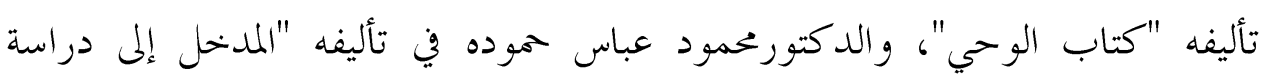

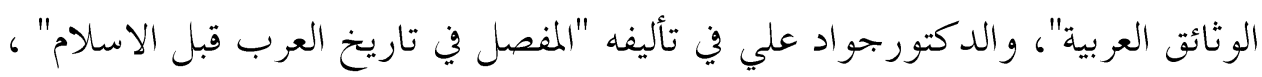

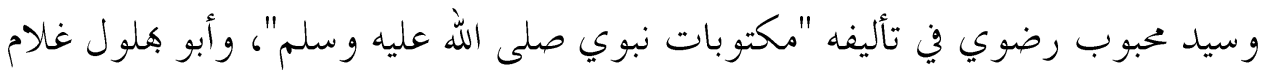

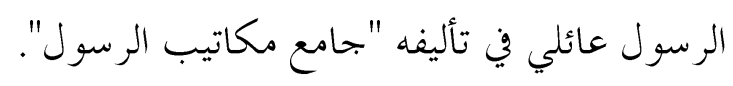
النماذج من معاهدات البي صلى الله عليه وسلم من "بحموعةالوثائق السياسية للعهدالنبوي والخلافة الراشدة": معاهدتاه صلى الله عليه وسلم مع أهل جرباء وأذرح

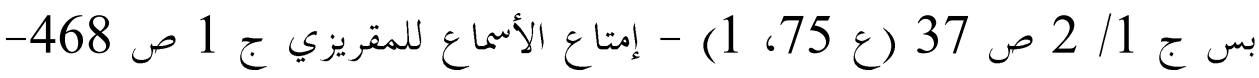

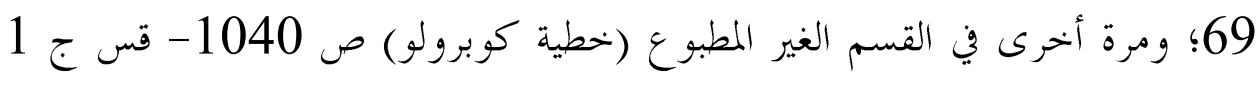


ص 297- عمخ ع 14 (عن الشامي) - فريدون ج 1 ص 34- مغازي الواقدي

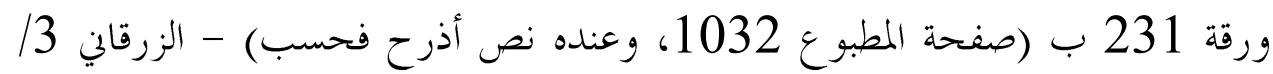

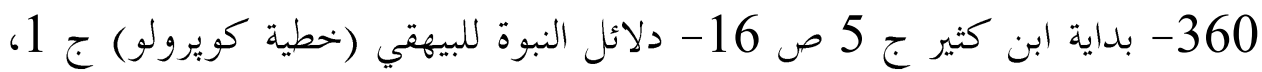

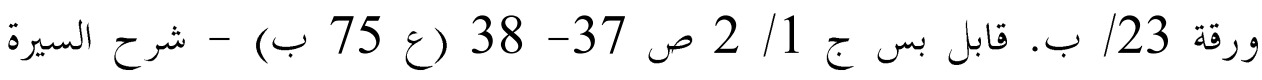

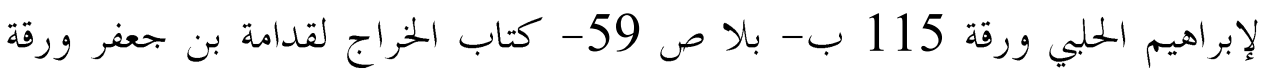
124 (خخطوطة باريس) -لسان العرب، مادة 》جربه" ، وقال: ابينهما مسيرة ثلاث

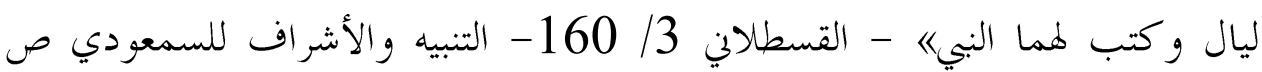

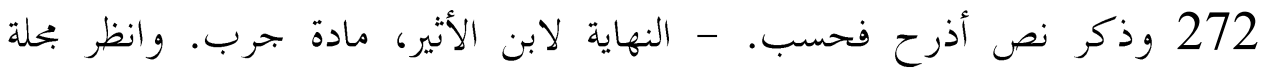

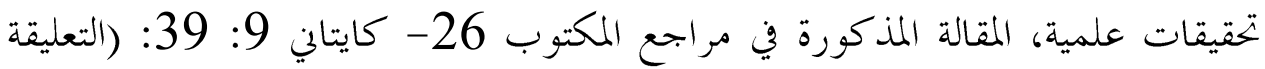

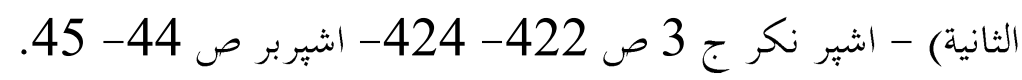
بسم الله الرحمن الرحيم هذا كتاب من محمد البي لأهل أذرح. إذهم آمنون بأمان الله ومحمد، وإنّ عليهم مائة

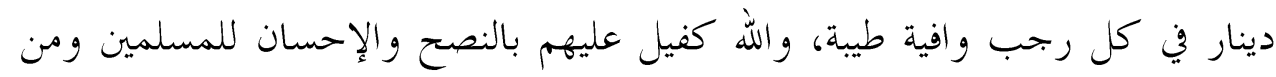

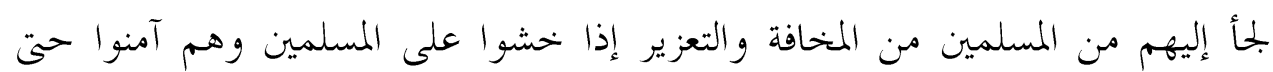
يحدث إليهم محمد قبل خروجهه. وفي إمتاع الأسماع للمقريزي ج 1 ص 468- 469 أنه كتب كتابين: الأول: لأهل جرباء ونصه: هذا كتاب من محمد البي رسول الله لأهل جرباء. إذهم

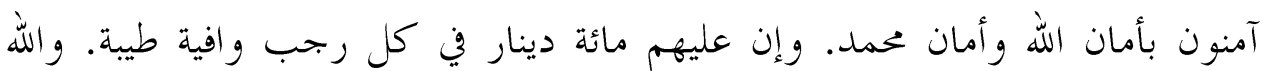
كفيل. الثاني: لأهل أذرح ونصه: بسم الله الرحمن الرحيم. من محمد البي رسول الله لأهل أذرح. 
إفمى آمنون بأمان الله وأمان محمد. و إن عليهم مائة دينار في كل رجب وافية طيبة. والله

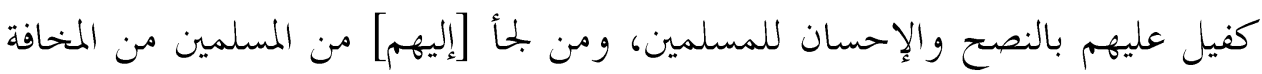
والتعزير إذا خشو ا على المسلمين وهم آمنون حتى يحدث إليهم محمد قبل خروجه.

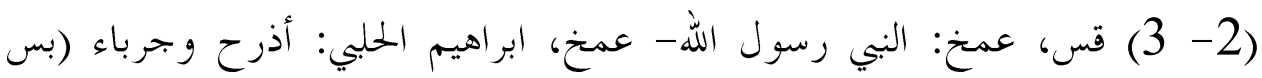
رواية: 年 جرباء وأذرح) - قس، عمخ، بس في رواية: أمان الله وأمان محمد- الواقدي: ... من

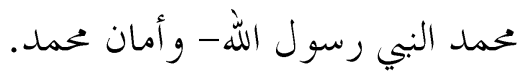
(4- 5) قس: الإحسان إلى المسلمين- الواقدي: لجأ ... - قس: المخافة ...

$$
\begin{aligned}
& \text { (6) عمخ: فهم- عمخ: محمد من قتل أو خروج. } \\
& \text { (4- 6) إبر اهيم الحلبي، بس في رواية: كفيل عليهم ... }
\end{aligned}
$$

$$
\text { بس ج } 1 \text { / } 2 \text { ص } 28 \text { (ع 44) - بلا ص 60- عمخخ ع } 25 .
$$

قابل بس ج 1/ 2 ص 38- الخراج لقدامة ورقة 124- إمتاع الأسماع للمقريزي ج

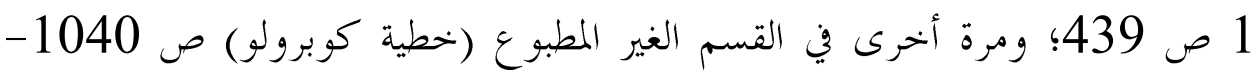
مغازي الواقدي، ص 1032- الحلبي 3/ 160 و انظر بحلة تحقيقات علمية، المقالة

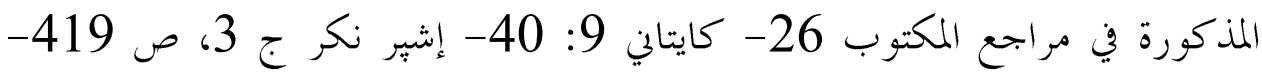

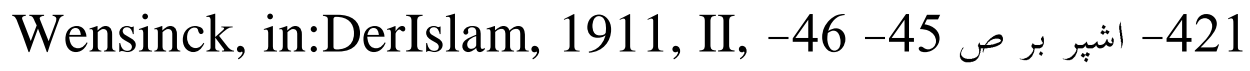
286- 91- Leszynsky, DieJuden in Arabien, Berlin 1910, - p. $107 \mathrm{ff}$

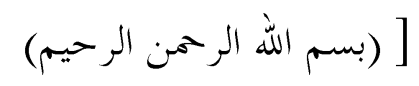

من محمد رسول الله] إلى بني جنبة وإلى أهل مقنا. 
أما بعد: فقد نزل علىّ آيتكم راجعين إلى قريتكم، فإذا جاءكم كتابي هذا فإنكم آمنون،

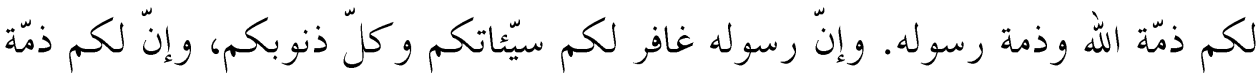
الله وذمة رسوله، لا ظلم عليكم ولا عدى. و إنّ رسول الله جار لكمم مما منع منه نفسه.

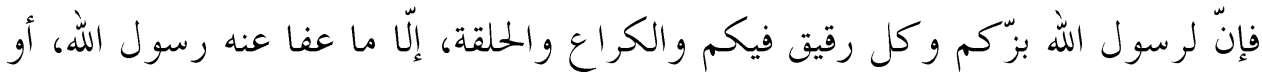

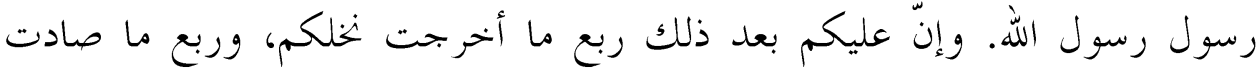

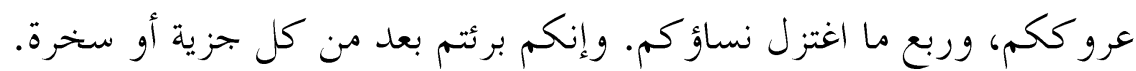
فإن سمعتم وأطعتم، فإنّ على رسول الله أن يكرم كريمكم، ويعفو عن مسيئمم. أما بعد فإلى المؤمنين والمسلمين: من أطلع أهل مقنا بخير فهو خير له، ومن أطلعهم بشرّ فهو شرّ له. - مله

وإن ليس عليكم أمير إلّا من أنفسكم، أو من أهل رسول الله صلى الله عليه وسلم.

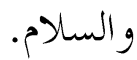

$$
\begin{aligned}
& \text { [و كتب علي بن أبى طالب في سنة تسع] . } \\
& \text { (2-1) }
\end{aligned}
$$

(2) بلا: حبيبة (بس في نسخة، عمخ، ابن حديدة: حينة) .

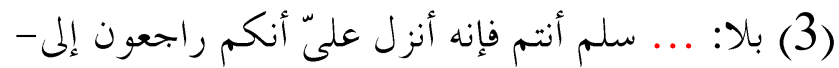

(4) بلا: آمنون ولكمم- ابن حديدة، بلا: وإن رسول الله- مغازي الواقدي: آمنون

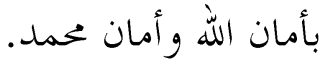

(4- 7) بلا: وإن رسول الله قد غفر لكم ذنوبكم وكل دم اتبعتم به، لا شريك لكم

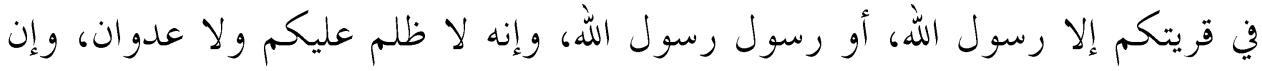
رسول الله يجير كم مما يجير نفسه. (8) ابن حديدة: وإن- بس في نسخة: بركم وكل (بلا: بز كم و ... رقيقكم) 


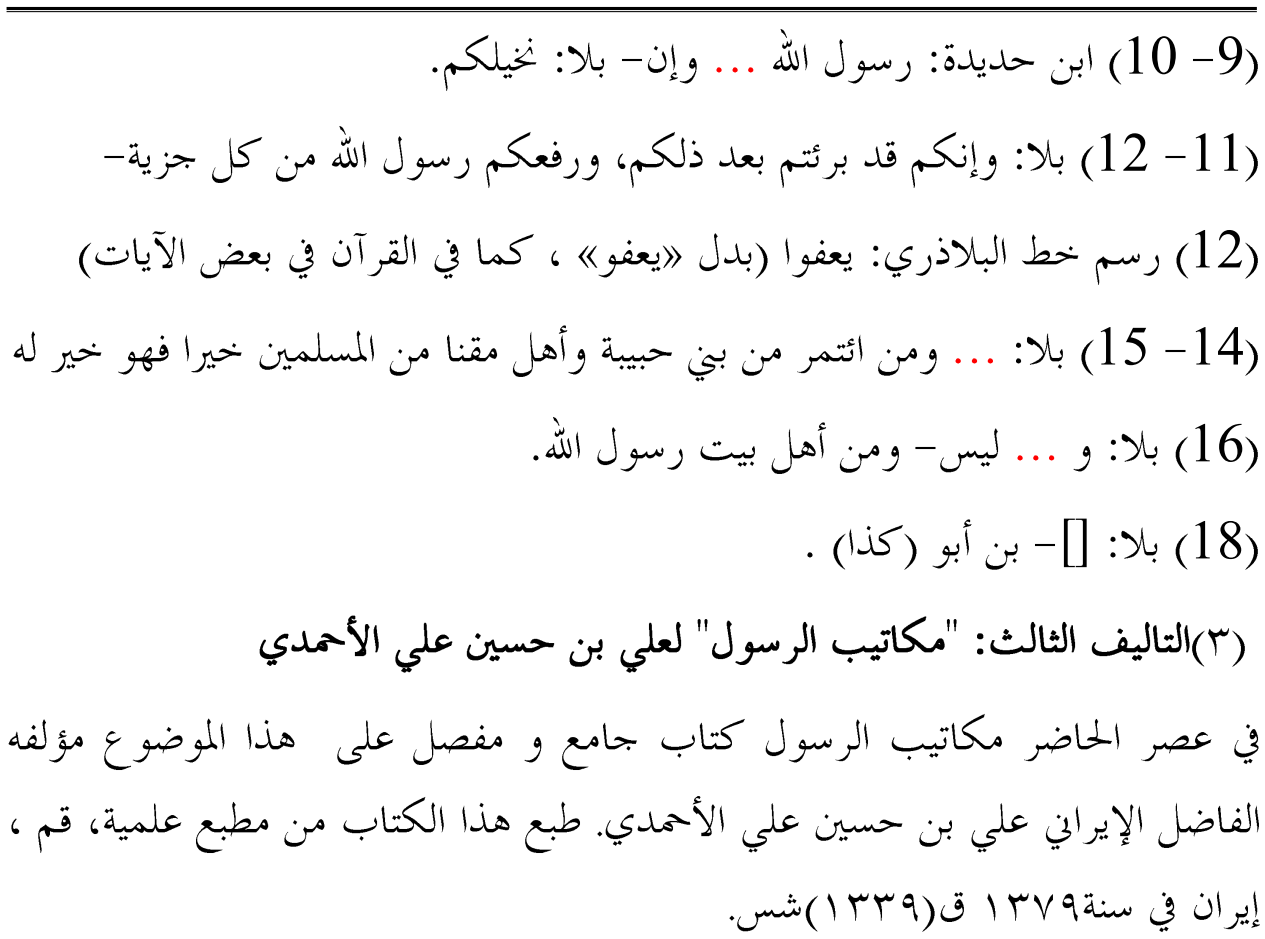

النقد:سنة النشر بحسب الطريق الإيراين لا بطريق مروج.

يشتمل هذا الكتاب على مجلدين متوسطين. اهتم المؤلف مع تدوين المكتوبات بشرحها وتسهيل المقامات الصعبة ولوأن محققاته ليست بصائبة في أكثر الأماكن ولكن مع ذلك هذاكدح جيد.

النقد:يأسفي أن هذا الكتاب ملوث بمثالب الصحابة رضي الله عنهم 11 الكتاب يشتمل على ثلاثة فصول، في الفصل الأول ذكر المكاتيب التي كتب النبي صلى الله عليه و سلم إلى ملو ك الدول وسادات القبائل وفيها تسعة و عشرون مكتو باً. (1) كتابه إلى كسري' ملك الفرس (Y) كتابه إلى المقوقس(ب) كتابه إلى المقوقس على نقل الواقدي (†)كتابه إلى الهلال صاحب البحرين(ه)كتابه إلى قيصر ملك

${ }^{11}$ Muhammad Abdul Shaheed, 25. 


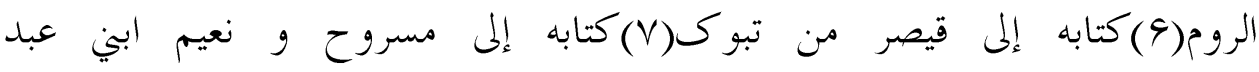

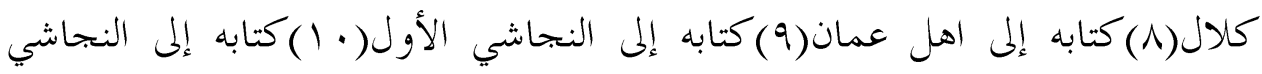

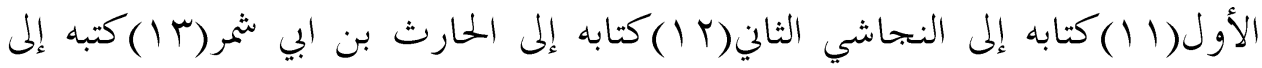

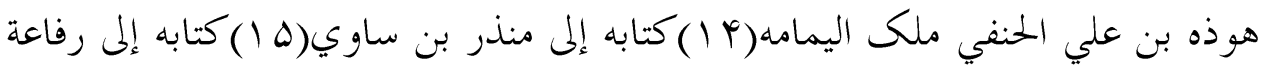

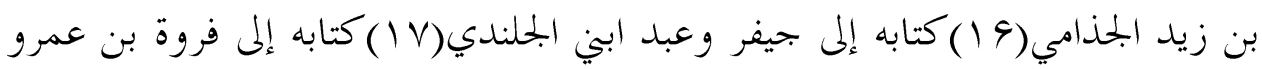

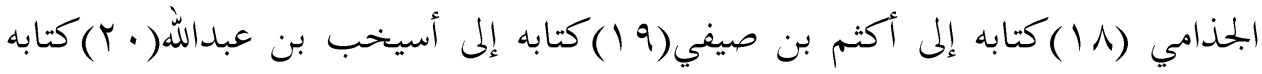

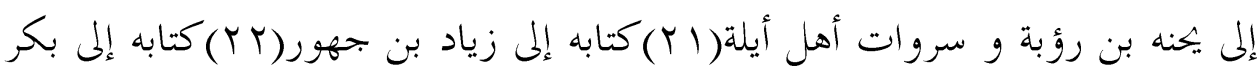

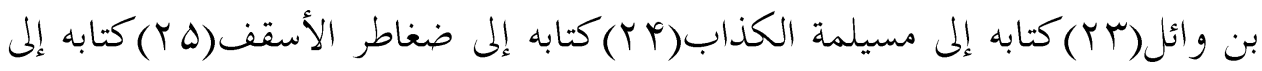

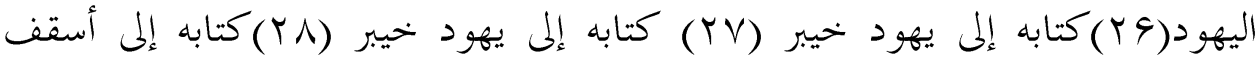

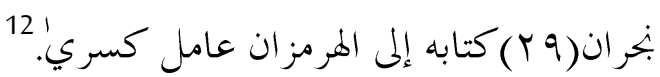
وفي الفصل الثاني اندرج المكاتيب التي كتب البي إلى العمال والأمراء وفيه Vا مكتوباً.

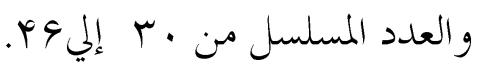
(1) كتابه إلى خالد بن الوليد (Y) كتابه إلى ملو ك خيبر (Y) كتابه لعمرو بن حزم

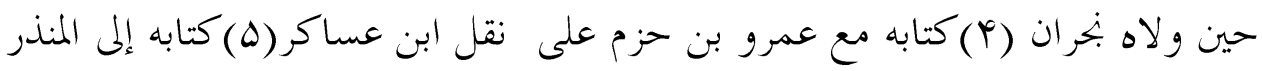

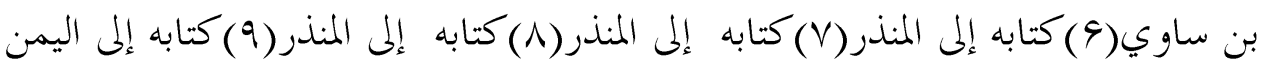

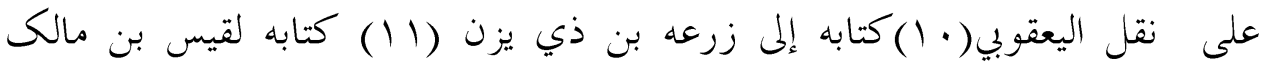

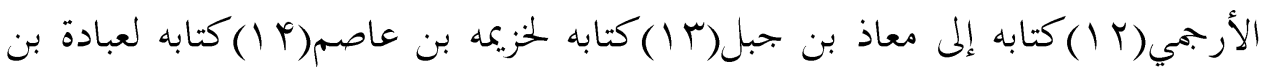

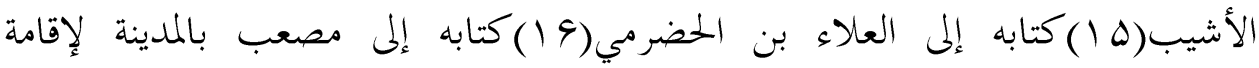

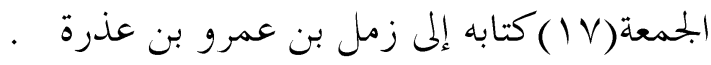

${ }^{12}$ Ali bin Hussain Ali Al Ahmadi, Makateeb Ul Rasul (Qum, Iran: Al Maktabatul Elmia, n.d.), 90-180. 
في الفصل الثالث ذكر المؤلف الوثائق المكتوبة التي تشتمل على معاهدات البي ومكتوبات

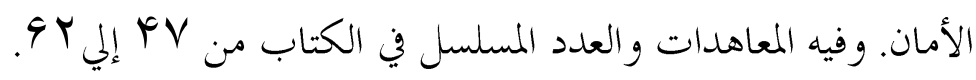
(1) كتابه بين المهاجرين والأنصار ويهود يثرب(؟)كتابه لوفد ثقيف(ب) كتابه إلى

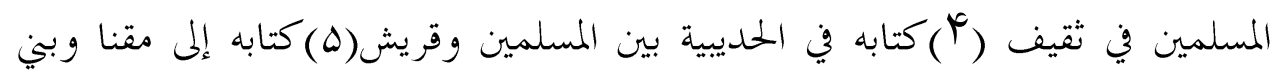

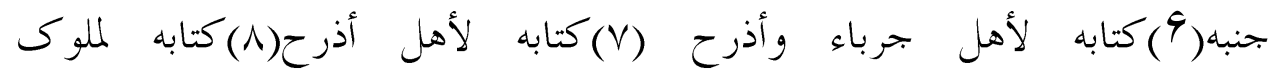

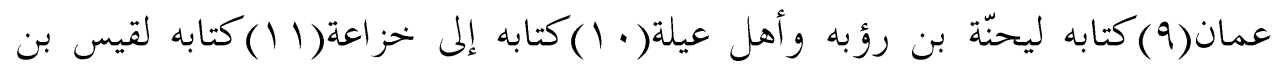

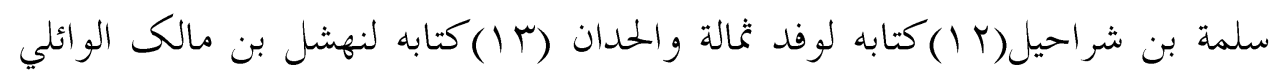

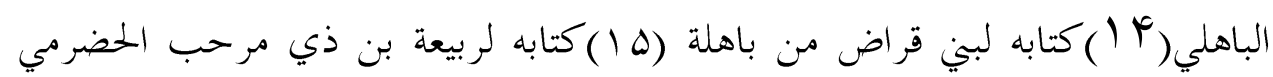

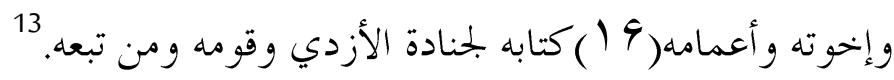

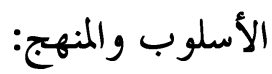

الختار المؤلف أسلو با منفرداً فنقل أولاًمتن المكتوب ثم ذكر المصادر المتعلقة الأخري تحت

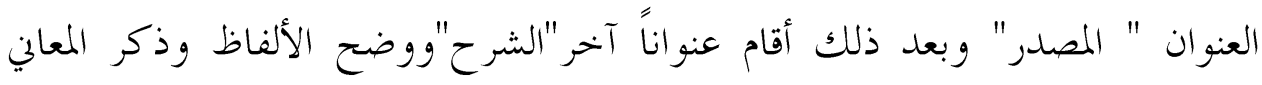

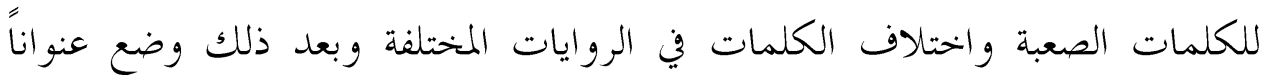

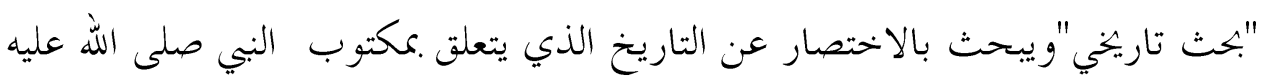

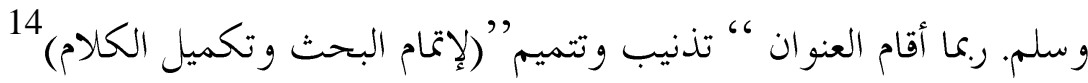

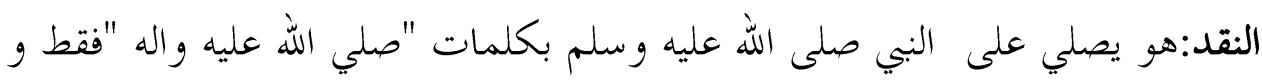
لكن ذكرنا في جميع المقامات "صلي الله عليه واله وسلم".

${ }^{13}$ Ali bin Hussain Ali Al Ahmadi, 241-314.

${ }^{14}$ Ali bin Hussain Ali Al Ahmadi, 183-240. 


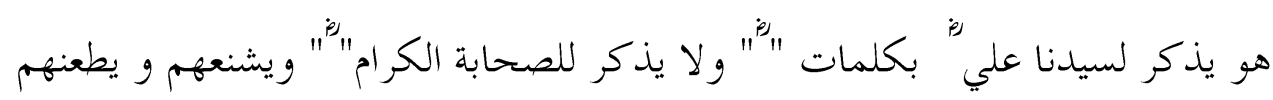
بسلاسة الكالام كما يأتي في المكتوب الآتي يذكر أبا موسي الأشعري بكلمة "الرجل" بالكر اهة تحت عنو ان تذنيب و تتميم. مثلاً

"فلم يدرك الرجل حياة النبي صلى الله عليه وسلم إلا بعد خيبر في خلال تلكم الغزوات والسرايا فرجع سنة تسع إلى اليمن وأدب قومه من نفسياته وإيمانه المتعرق!!! ما نقضوه بُعيد وفاة الرسول صلى الله عليه وسلم ، وقاتلوا المسلمين قاتلوا أمير المؤمنين عليا عليه السالام بعد ذلك معاوية". هذا الأسلوب كريه جدا ومبين على بغض الصحابة الكرام رضي الله عنهم أجمعين.

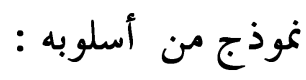
كتابه صلى الله عليه وسلم إلى اليمن على نقل اليعقوبي بسم الله الرحمن الرحيم هذاكتاب من محمد رسول الله إلى أهل اليمن، فاني أحمدالله إليكم الذي لاالله الا هو؛ وقع بنا رسولكم مقدمنا من أرض الروم، فلقينا بالمدينة فبلغنا ما أرسلتم به؛ وأخبرنا ما أسا كان قبلكم؛ ونبأنا بإسالاكمم، وأن الله قد هداكم إن أصلحتم وأطعتم الله وأطعتم

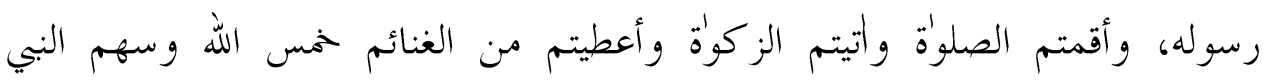
و الصفي، وما على المؤمنين من الصدقة عشر ما سقي البعل وسقت السماء وما سقي بالقرب نصف العشر وأن في الإبل من الأربعين حقة، قد استحقت الرحل؛وهي جذعة، و

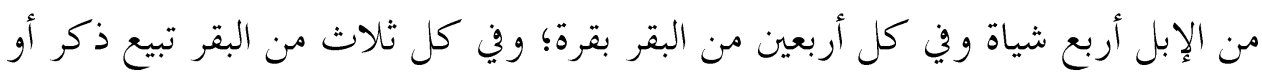

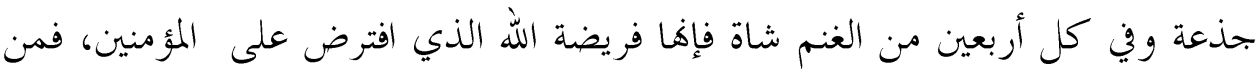
زاد خيرا فهو خير له،فمن أعطي ذلك وأشهد على إسلامه وظاهر المؤمنين على الكفرين، 
فإنه من المؤمنين له ذمة الله وذمة رسوله محمد رسول الله، وأنه من أسلم من يهودي أو أو اله

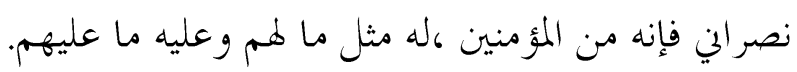

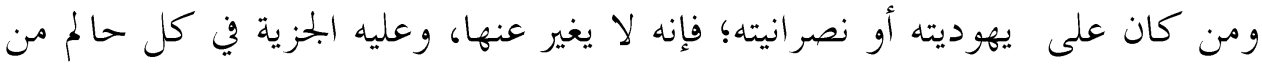

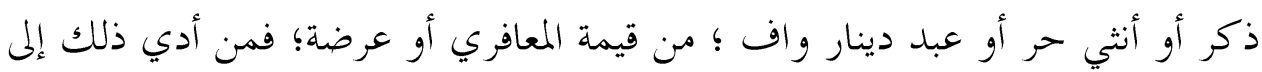

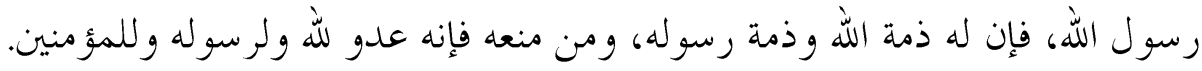
و أن رسول الله مولي غنيكم وفقير كم ؛ وأن الصدقة لا تحل لخممد وأهله؛ إنما هي زكوةّ

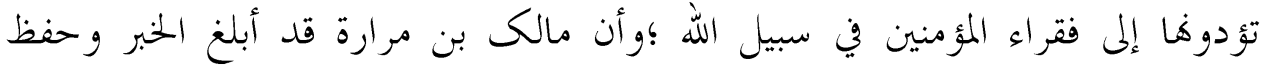

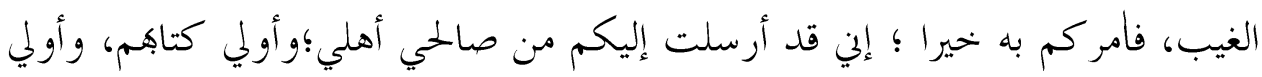

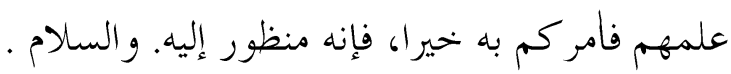

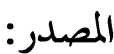

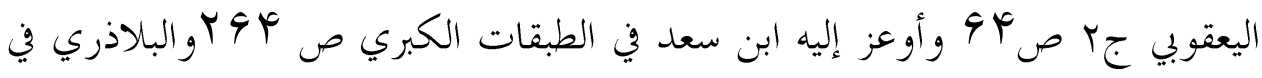

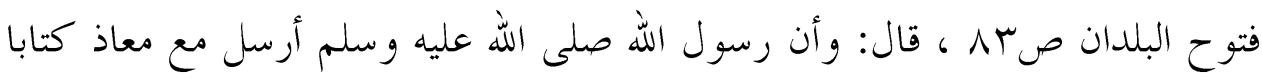

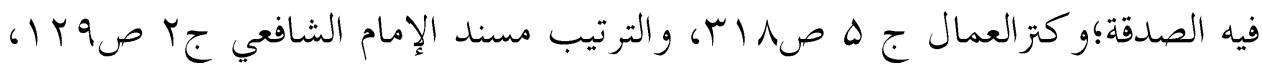

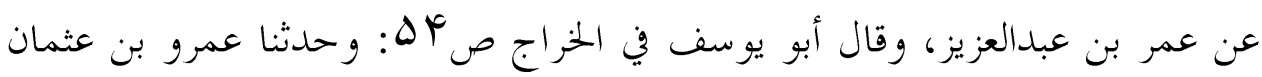

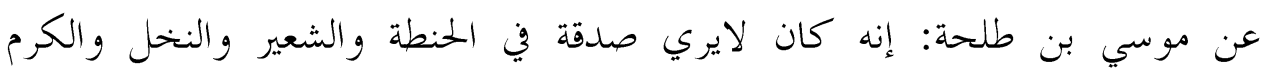

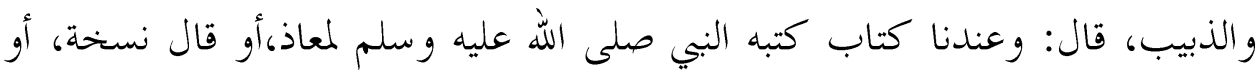
و وجدت نسخة هكنا.

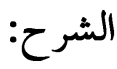
قوله:أصلحتم أي عملتم صالحا، أو أصلحتم أنفسكم ،و الصفي عطف على سهم البي

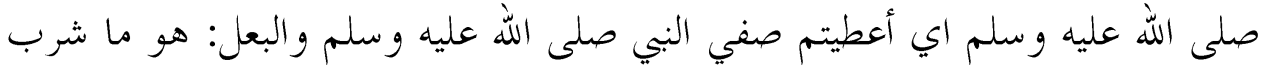

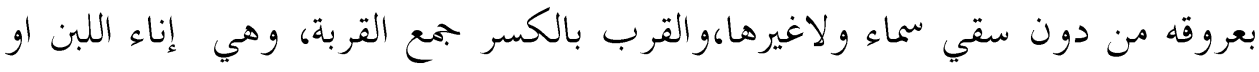

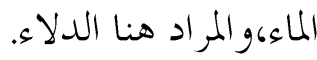


المولي من ولي يلي ولاية بكسر الواو بمعني الناصر ، والولاية تولي الأمر والنصرة، والذي

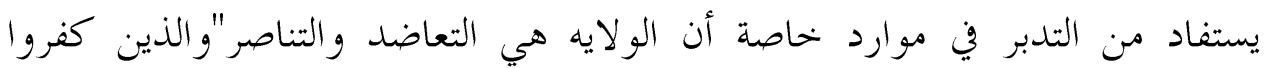

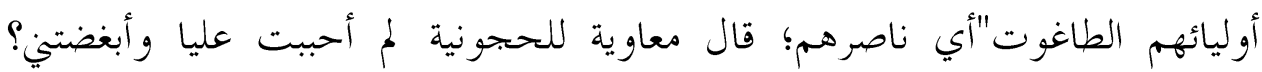

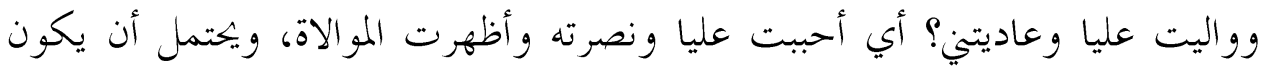

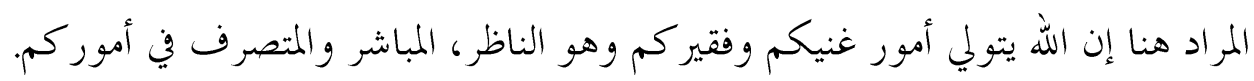

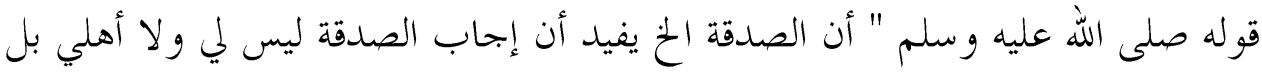

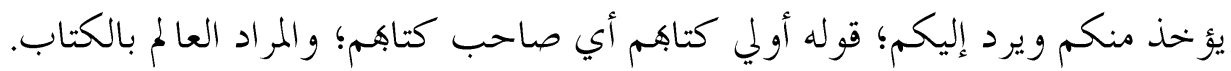
بحث تاريني:

حامل الكتاب هو معاذ بن جبل ( صرح به اليعقوبي جrصب و، وأوعز إليه البلاذري

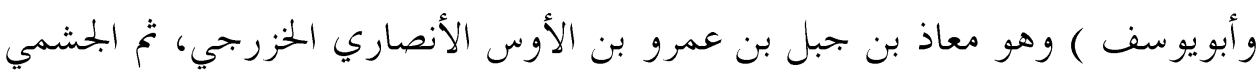

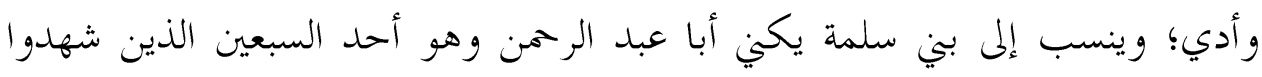

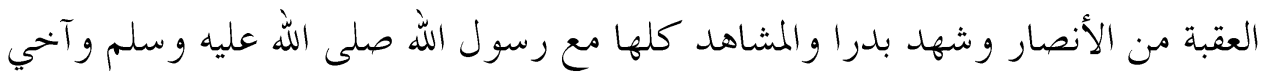

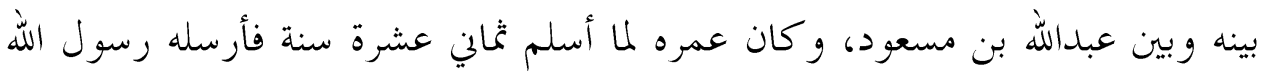

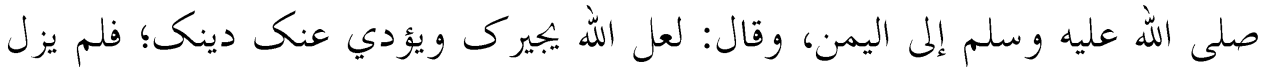
باليمن حتي توفي رسول الله (ص) وتوفي في طاعون عمواس سنة ثمان عشرة؛ والأول الكّل أصح ، و كان عمره ثمانيا وثلثين سنة وقيل ثلاث وقيل وتيل أربع وثلالثون سنة 15

${ }^{15}$ Ibn e Kathir, Abu al Fida,Ismaeel bin Umar bin Kathir Al Qurashi Al Dimishqi, Al-Bidayah Wa al-Nihayah, vol. 5 (Beirut: Dar Al Ahya al Turath Al Arbi, 1988), 99-103. 
استخلف رسول الله صلى الله عليه وسلم عتاب بن أسيد بمكة بعد الفتح، وخلف معه آلها

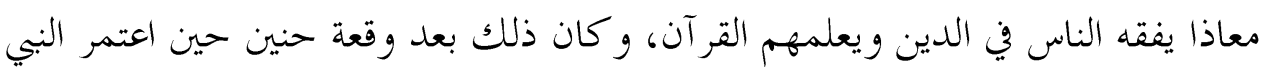
صلى الله عليه وسلم من الجعرانة 16 وفي البداية والنهاية جه ص . . ا قال رسول الله صلى الله عليه وسلم لمعاذبن جبل حين

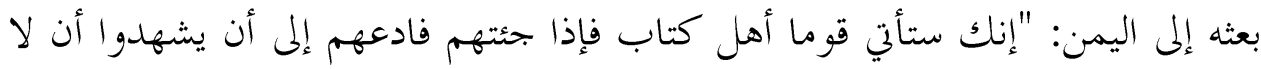

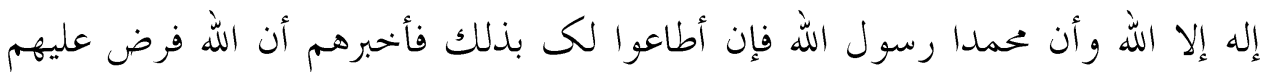

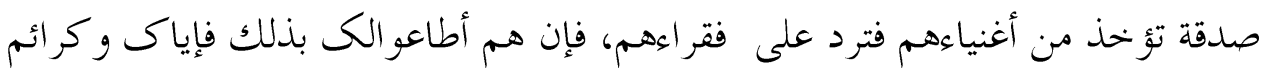

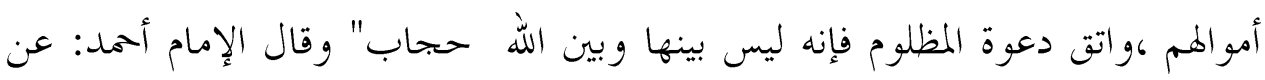

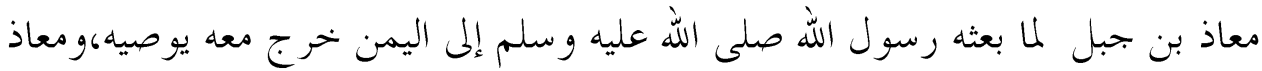

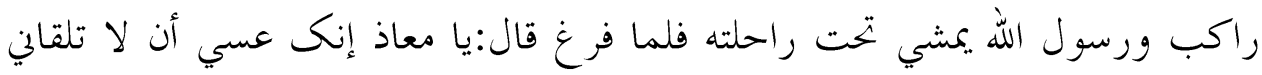

$$
\text { بعد عامي هذا ولعلك تمر بمسجدي وقبري. }
$$

وأورد العلامة البحلسي(ره)في البحارجV| وصايا رسول الله صلى الله عليه وسلم لمعاذ بكاذ

$$
\text { بن جبل طويلة. }
$$

و كان معاذ قاضيا و حاكما ومعلما ومؤدبا كما في البداية والنهاية.

$$
\text { تذنيب وتمميم }
$$

بعث رسول الله صلى الله عليه وسلم مع معاذ رسلا إلى اليمن، ليفقهو الناس ويعلموهم القرآن ويشروهم وينذروهم ، ونهن نذكرهم ليكثر الفائدة،ويزيد العائدة فنقول: بعث صلى الله عليه وسلم مع معاذا جمعا من الصحابة منهم.

${ }^{16} \mathrm{Al}$ Tabri, Abu jafar, Muhammad Bin Jarir bin Yazid bin Kathir,Al Amli, Tarikh Al-Rusul Wal-Muluk, 2nd ed., vol. 2 (Beirut: Dar ul Turath, 1387H), 362. 
النقد: قال المؤلف هنا " مع معاذا" والصحيح مع معاذ. لأن بعد "مع " يكون المعمول

على غخلاف غير مخلاف و كانا قريبين يزور أحدهما الأخر.أبو موسي إسمه عبدالله بن قيس، أسلم بمكة وهاجر إلى الحبشة وقدم إلى المدينة بخيبر،وعن الواقدي: أنه ليس من

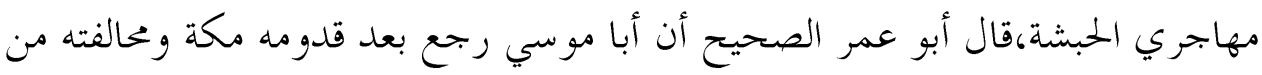

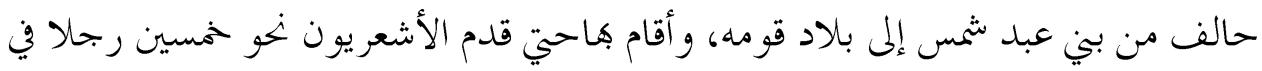

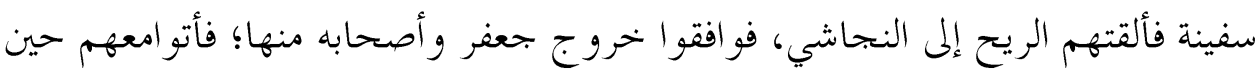

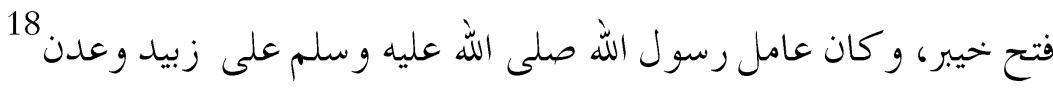
أقول: هو من الأشعرأو أشعر بن أدد (وفي النهاية سبامكان أدد) كانوا يسكنون زبيد رسيد

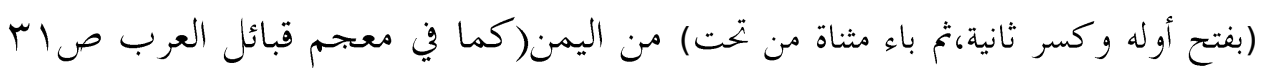

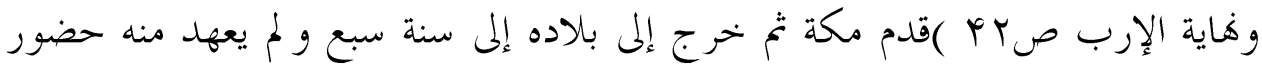

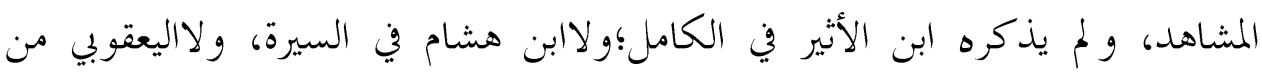

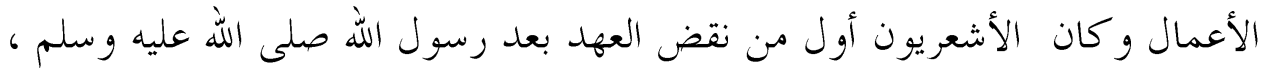

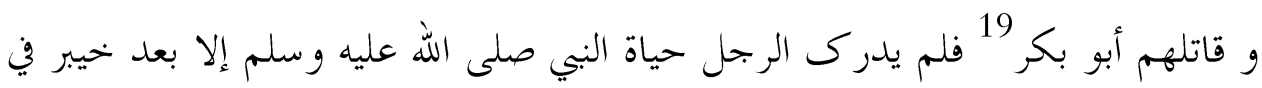
خلال تلكم الغزوات والسر ايا؛ فرجع سنة تسع إلى اليمن وأدب قومه من نفسياته وإيمانه

${ }^{17}$ Ibn e Kathir, Abu al Fida,Ismaeel bin Umar bin Kathir Al Qurashi Al Dimishqi, Al-Bidayah Wa al-Nihayah, 5:99.

${ }^{18}$ Ibn al-Athir Izzad-Din Abu al-Hassan Ali ibn Muhammad ibn Muhammad ash-Shaybani, Usd Al-Ghabah Fi Marifat al-Sahabah, 1st ed., vol. 5 (Beirut: Darul Kutubul Ilmiyyah, 1994), 3.

${ }^{19}$ Kahala Umar ibn Rida ibn Muhammad Raghib, Mujam Qabailil Arab, 7th ed. (Beirut: Muassat ul Risala, 1994), 31. 
المتعرق !!! ما نقضوه بُعيد وفاة الرسول صلى الله عليه وسلم ، وقاتلوا المسلمين قاتلوا

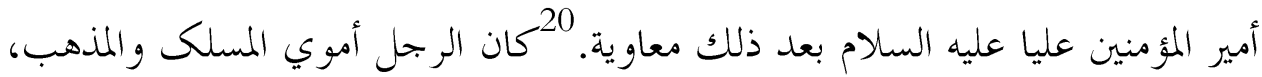

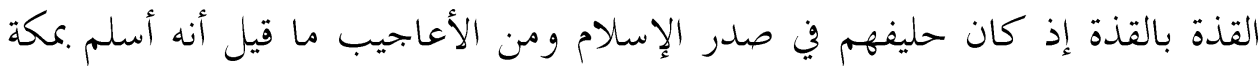

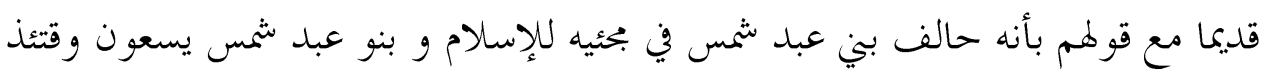

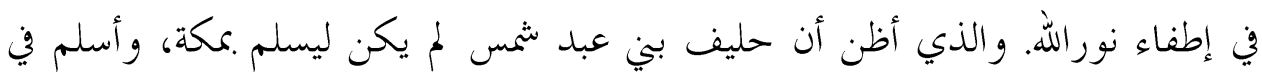

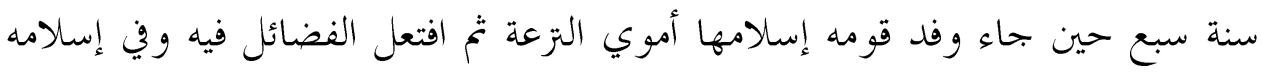

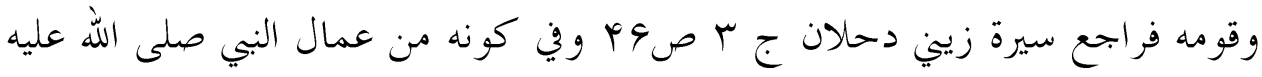

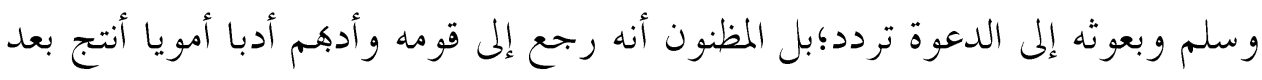

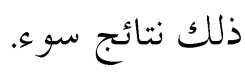
كان عبدالله بن قيس بحانبا لعلي يخذله ويخذل الناس عنه في ضؤلة عقله ومهانة نفسه

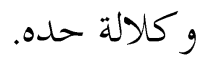
r.عبدالله بن زيد(وفي أسد الغابة عبدالله بن رواحة)والأول أنبت لما مر آنفا ذكره ابن

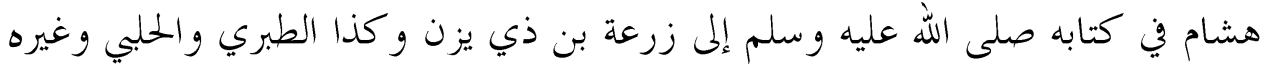

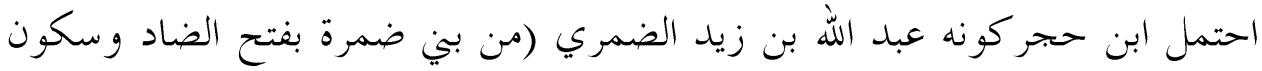

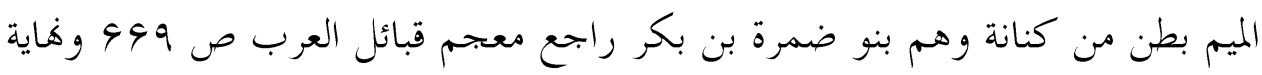

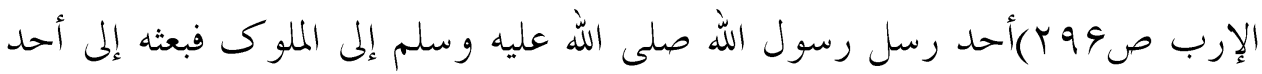

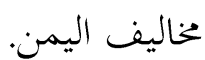

${ }^{20}$ Umar ibn Rida ibn Muhammad Raghib, 31-32. 
rا.مالك بن عبادة قال ابن الأثيرهو مالك بن عبادة الممداني قدم على البي صلى الله

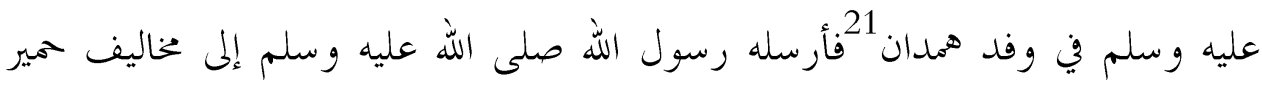
وأمرهم بإكرام الرسل وهو منهم.

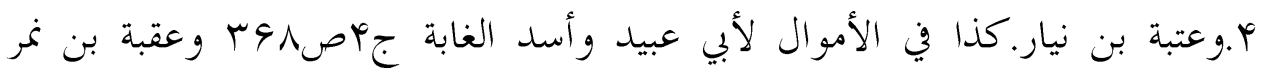

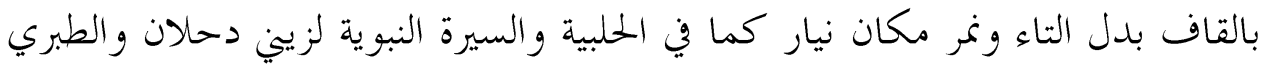

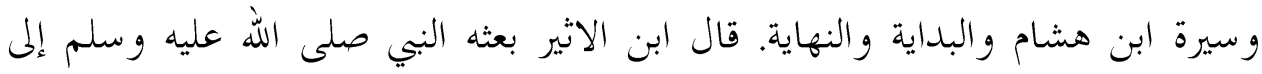

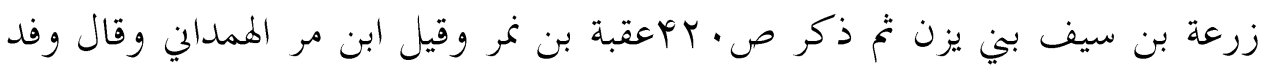

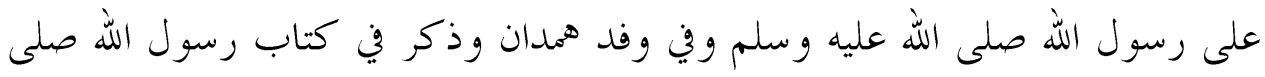

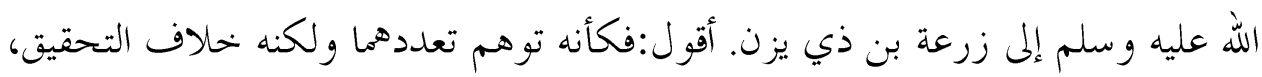

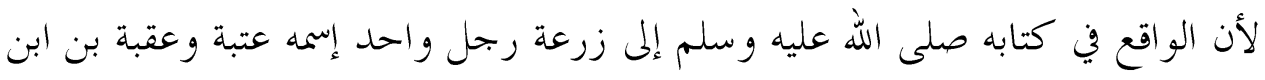

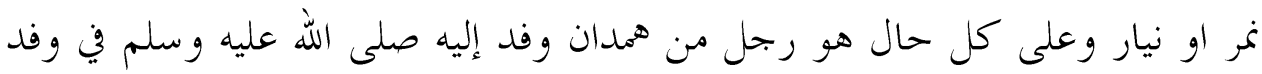

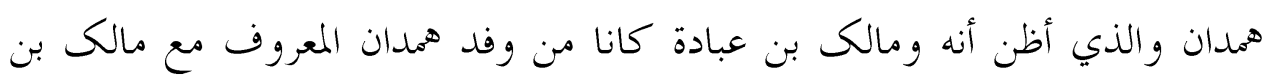
نمط(سيكون يأتي ذكر هذا الوفد في ذيل كتابه صلى الله عليه وسلم لهم). ه.مالك بن مرارة الرهاوي من بي رهاء بامد (بطن من كهلان من القحطانية) وهم

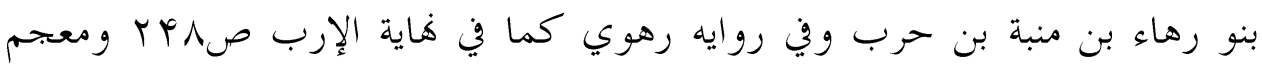

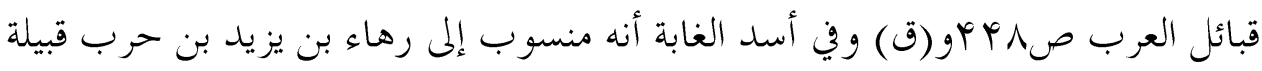

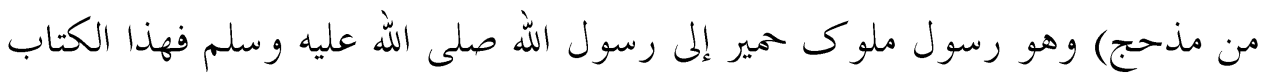

${ }^{21}$ Ibn al-Athir Izzad-Din Abu al-Hassan Ali ibn Muhammad ibn Muhammad ash-Shaybani, Usd Al-Ghabah Fi Marifat al-Sahabah, 1st ed., vol. 4 (Beirut: Darul Kutubul Ilmiyyah, 1994), 282. 
كالمنشور العام أرسله إلى قري اليمن وبلادها ومخالفيها ولذلك كانت الرسل ينتقلون من بلد إلى بلد ومن مخلاف إلى مخلاف 22 و كان رئيسهم معاذ بن جبل ونبل. وأرسل صلى الله عليه وسلم قبل ذلك إلى يخلاف همدان خالدا فلم يجيبوا إلى الإسلام

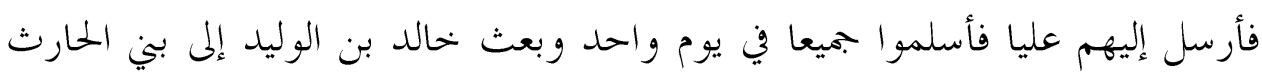

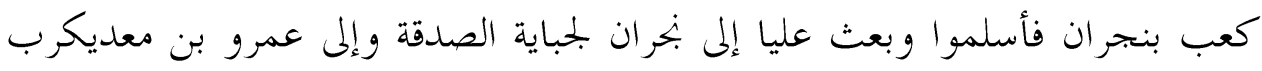

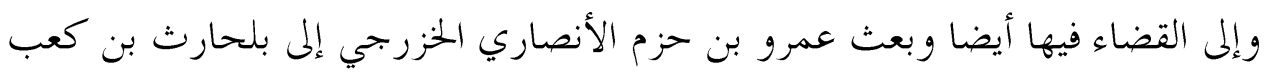

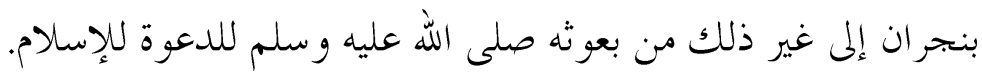
فمن سبر تاريخ الإسلام وتعرف نشوه و علل اعتلاءه ودخول الناس في دين الله أفو اجا

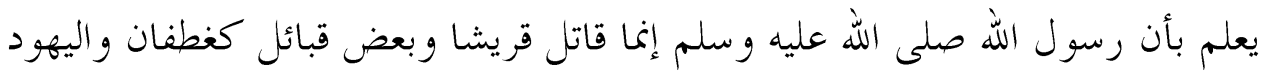

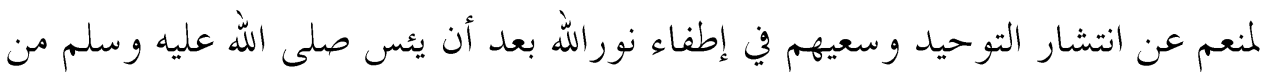

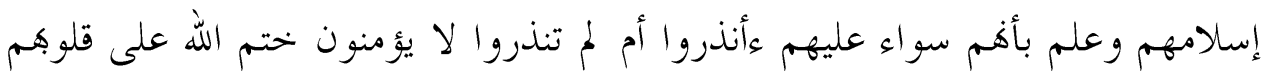

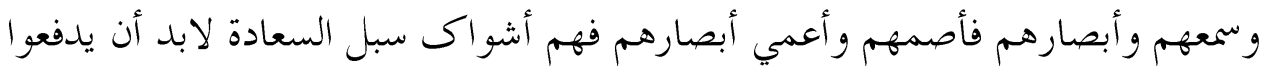

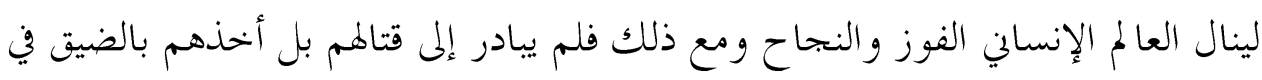

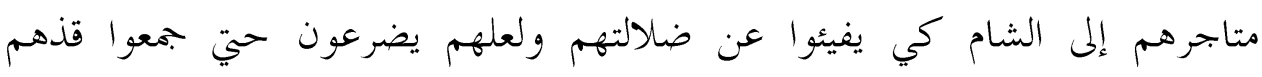

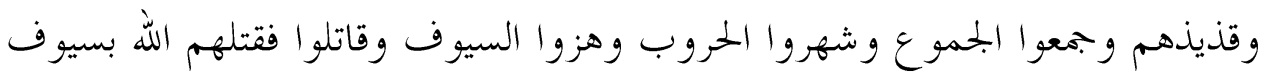
المسلمين.

فكان صلى الله عليه وسلم سعي في إعلاء كلمة التوحيد أسهل السبل وأبحح الطرق

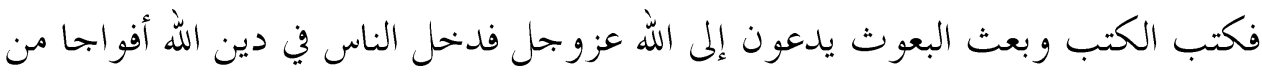
دون أي قتال وسفك دماء.

${ }^{22}$ Ibn e Kathir, Abu al Fida,Ismaeel bin Umar bin Kathir Al Qurashi Al Dimishqi, Al-Bidayah Wa al-Nihayah, 5:99. 
النقد: ههنا قال المؤلف في هذه العبارة "سواء عليهم ء أنذروا ام لم تنذروا لا يؤمنون"

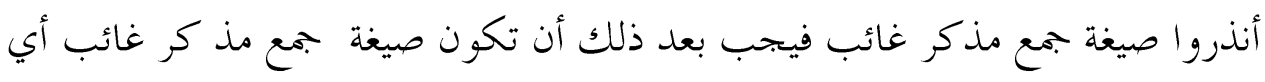
ينذروا مكان تنذروا.

ولذلك كثر المبلغون والبعوث إلى قبائل العرب في اليمن واليمامة والبحرين وعمان و دمشق وسماوة وكتب إلى ملوك الدنيا فلم مضم سنة تسع من الهجرة إلا ذكر الإسلام في أقطار العالم وعرف الناس التوحيد وللة الحجة البالغة.

(†) التاليف الرابع: نشأة الدولة الإسلامية على عهد رسول الله صلي الله عليه

$$
\text { وسلم: للدكتورعون الشريف قاسم }
$$

هذه رسالة تحقيقية للدكتور عون الشريف قاسم ، قدم لنيل درجة الماجستير من جامعة

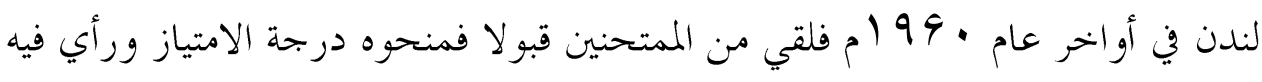

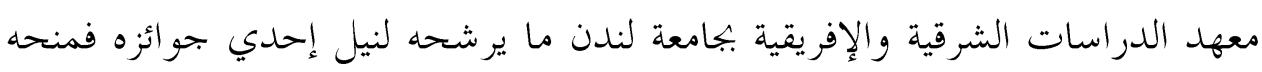
جائزة روفون قست (Rhuvon Guest) لأحسن دراسة عربية إسلامية بالمعهد

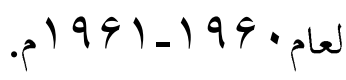

بعد عشرة سنوات ترجم إلى اللغة العربية وأجري القلم في كثير من جوانبه ،إضافة

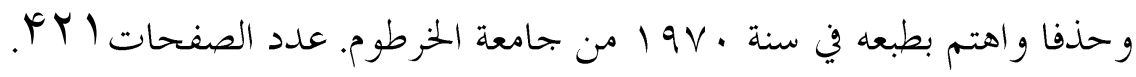
قسم المؤلف هذا التاليف إلى قسمين: القسم الأول: بعنوان دراسة النصوص وفيه ستة

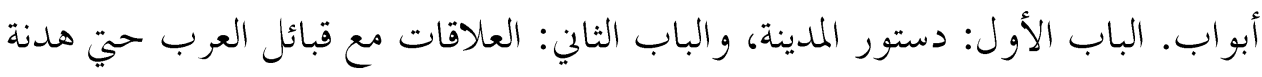

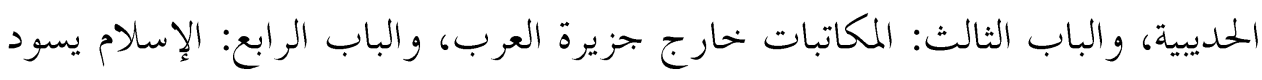

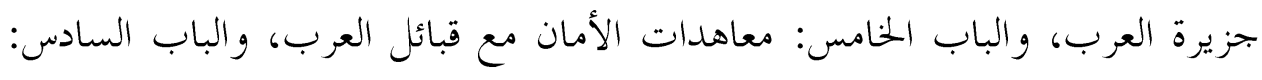
إقطاع النبي صلى الله عليه وسلم.

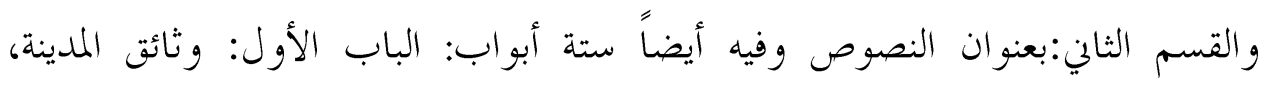

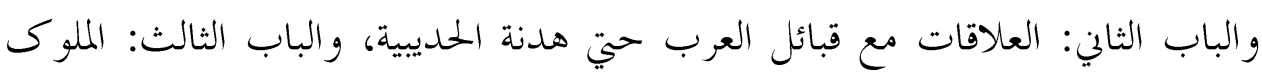


خارج جزيرة العرب، والباب الرابع: الاتفاقيات مع اليهود والنصاري، والباب الخامس: قبائل الشام، والباب السادس: إقطاع النبي صلى الله عليه وسلم.

$$
\text { الأسلوب والمنهج }
$$

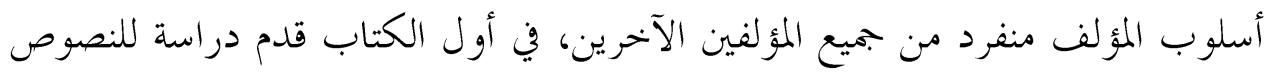

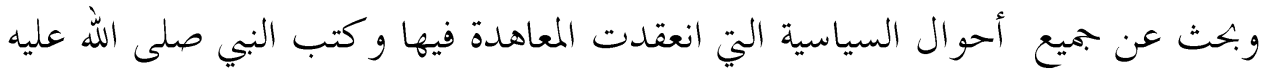

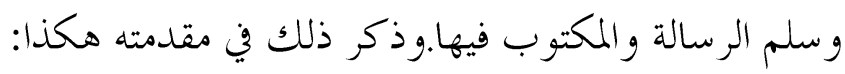
"كان قيام الدولة الإسلامية في المدينة المنورة وإمتداد نفوذها بالتدريج إلى معظم أجزاء

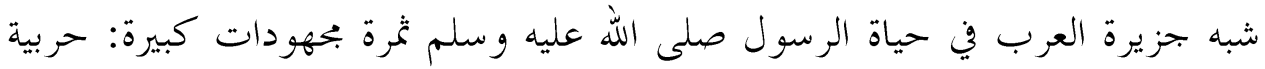

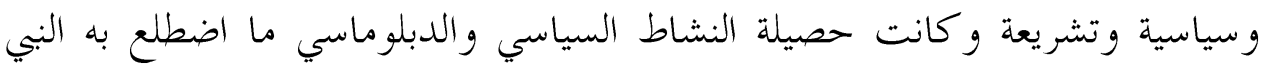

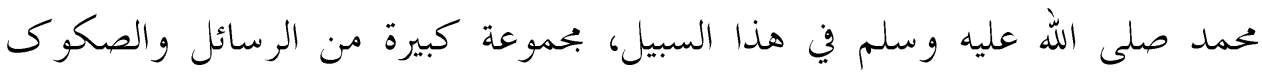

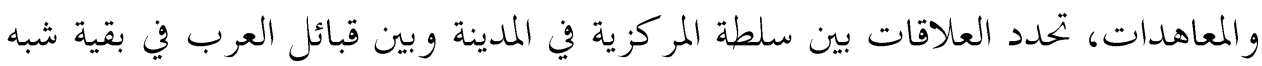
جز يرة العرب وقد اختلفت طبيعة هذه الوثائق وأهدافها باختلاف الظروف والملابسات

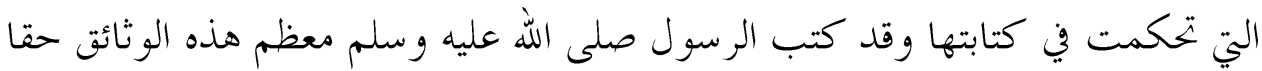

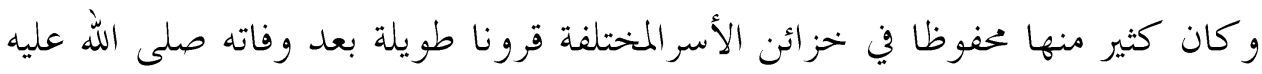

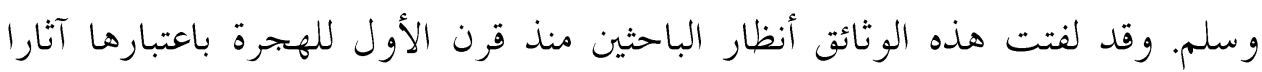

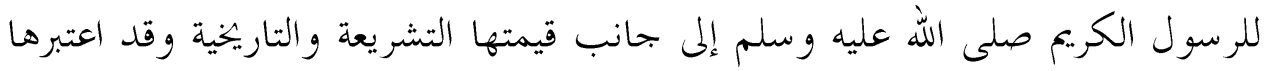
الرواة ضربا من الحديث النبوي ، ولذلك أرفقوا ما رووه عنها بسلسلة من الأسانيد

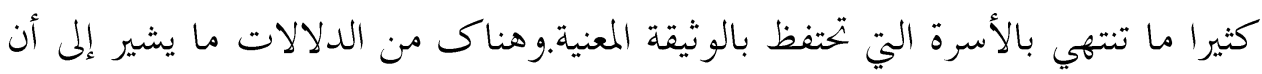

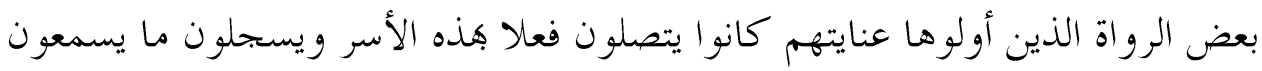
منها من مقال وقد نقلت النصوص في كثير من الحالات عن وثائق أصليه باقية". 23

${ }^{23}$ Aun al-Sharif Qasim al-Sudani, Nashat Ul Daula, Al Islamia, 2nd ed. (Beirut: Dar ul Kitab al Labnani, 1981), 9. 
بعد دراسة النصوص في القسم الثاني ذكر النصوص أي متون المكتوبات والمعاهدات ومر اجعها ومصادرها كثيرة متنوعة قديما وحديثا. قد بين في مقدمته التاريخ المختصر لمعاهدات البي صلى الله عليه وسلم وذكر أن أقدم

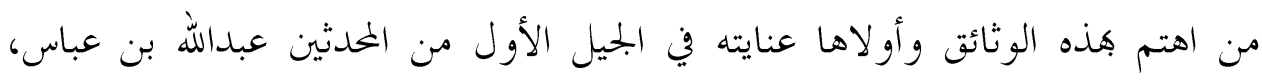

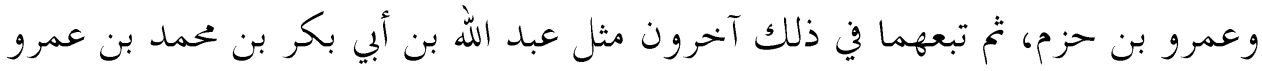

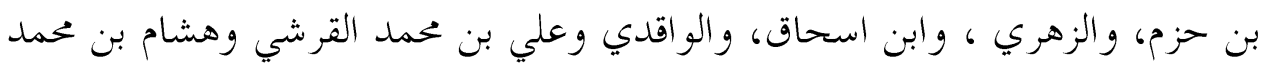
بن السائب الكبي وابن سعد و المدائي والطبري.

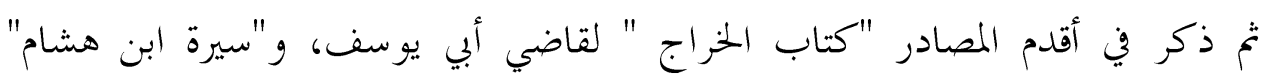

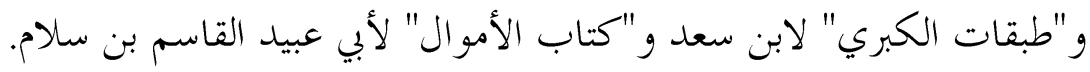

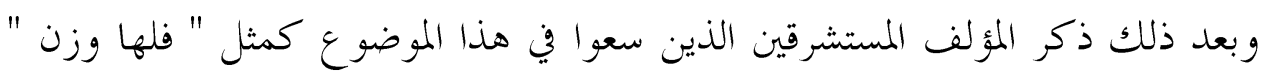

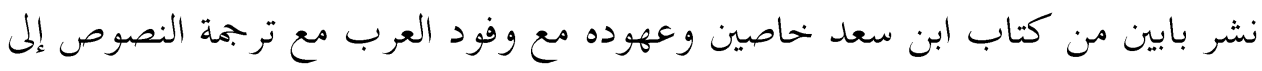

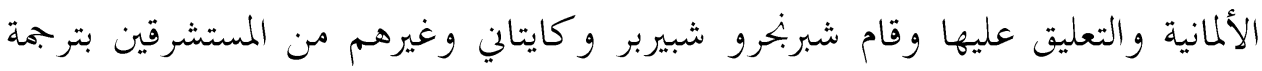

$$
\text { بعض النصوص ودراستها. }
$$

واعترف خدمات العلماء الهند في هذا البحال الذين جمعو النصوص المبعثرة في تصنيفاتم

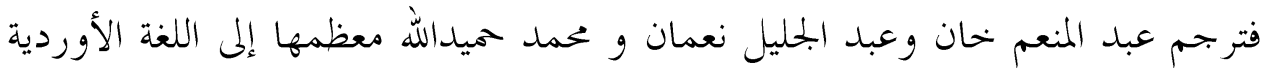

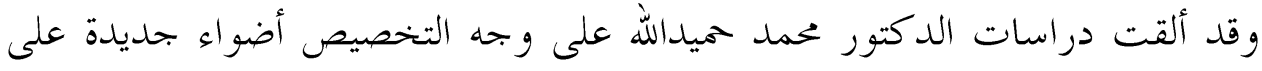
كثير من النصوص فإلى جانب رسالة الدكتوراة التي كتبها في الفرنسية عن هذا فالها

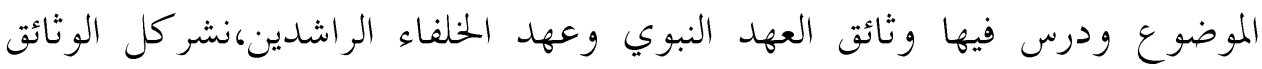

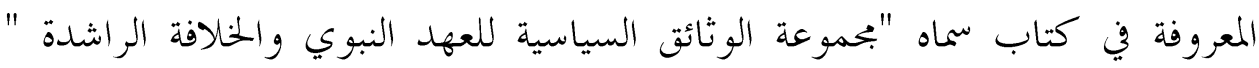
وصدره .مقدمة مفيدة. 
والمؤلف متأثر جدا من الدكتور محمد حميدالله واستفاد من تأليفاته كثيرا كما اعترف في

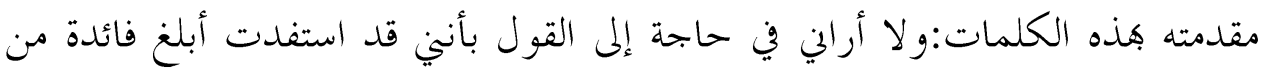

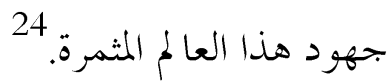

$$
\text { الأسلوب والمنهج }
$$

كان عمدة المؤلف في تقر ير صحة أي نص أن ينسب ما احتواه من مادة ما أمكن ، إلى

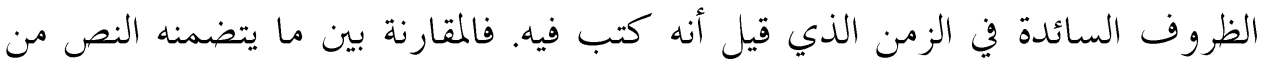

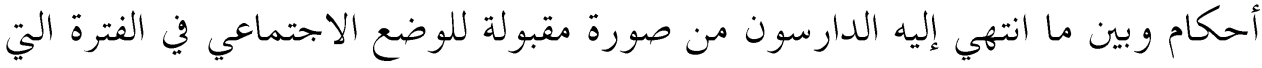

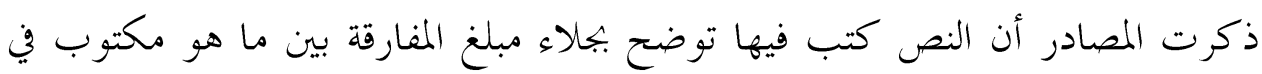

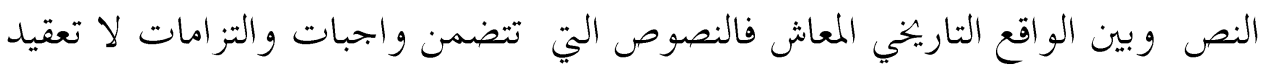

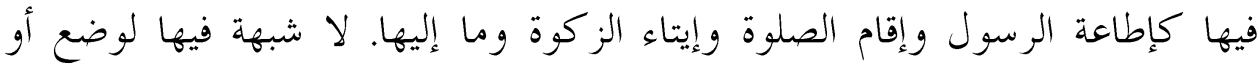

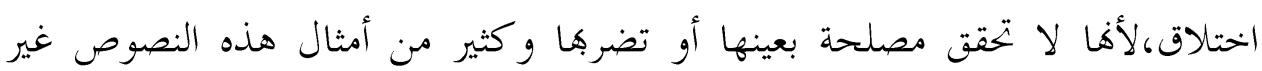
المعتقدة يستقيم مع الآية الكريمة:

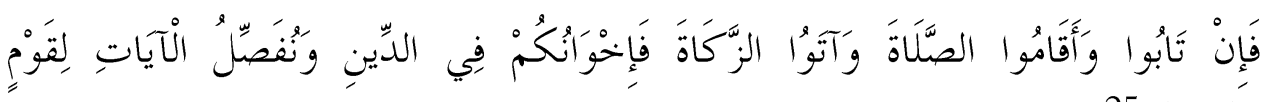

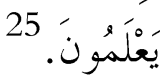

$$
\text { التي أنزلت في سورة التوبة في العام التاسع من الهجرة. }
$$

ذكر المؤلف أن هناك التوسع في جزئيات التشريع واصطلاحاته الدقيقة حيال النصوص.

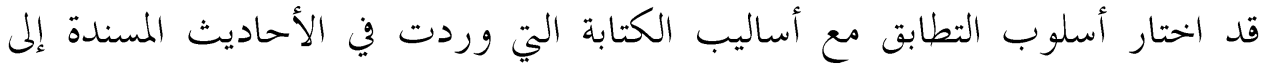

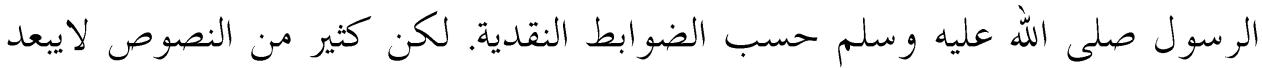

\footnotetext{
${ }^{24}$ Aun al-Sharif Qasim al-Sudani, 12.

${ }^{25}$ Al-Quran.9:11
} 
عن هذه الأساليب بل بعضها تشابه بأسلوب القرآن الكريم و لم تحدث الرواية المتصلة كبير تغيير في كثير من الحالات في شكله وترتيبه.

وضح المؤلف أن اختلاف الألفاظ في النصوص المختلفة دليل على ذلك أن النص المعني قد نقل عن أصل قديم مكتوب. و بين المؤلف مفارقات النحوية جديرة بالنظر كما توجد كلمة "أبو" في حالة الرفع

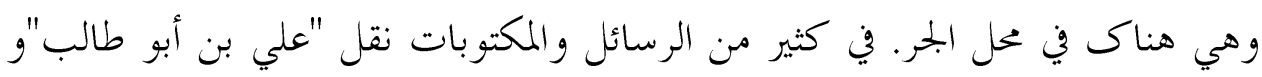

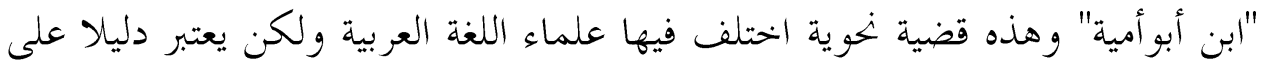
صحة النص عند الرواة المتأخرين.

في مقابل هذه النصوص"البسيطة" الخالية من التعقيد قسم آخر من النصوص فى بحال

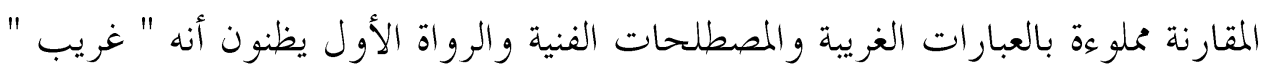
لكن اهتم المؤلف لاعتبار معظم ما وردت الغرائب في هذا الباب بتخريجات المتأخرين. قسم المؤلف هذه الدراسة بين مرحلتين، مرحلة أولية كان العنصر السياسي فيها هو

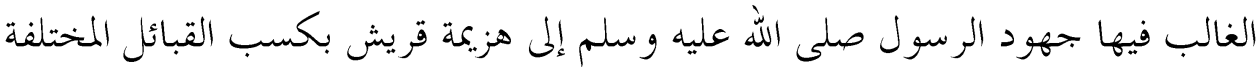

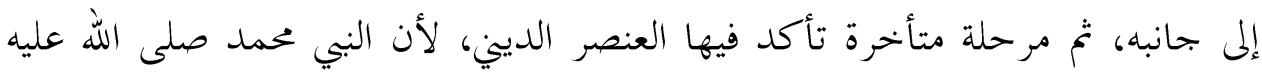

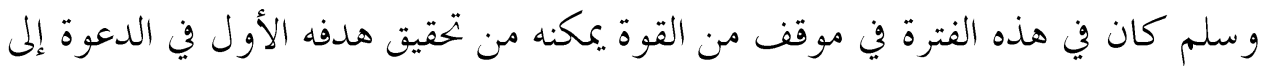

فكل الرسائل التي عالمها المؤلف في البابين الأولين من هذه الدراسة ترجع إلى المرحلة

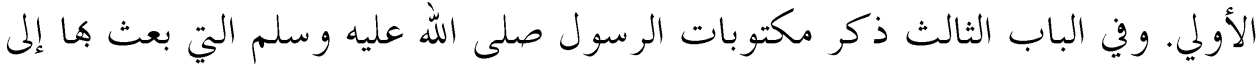

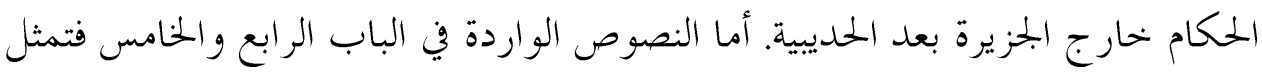

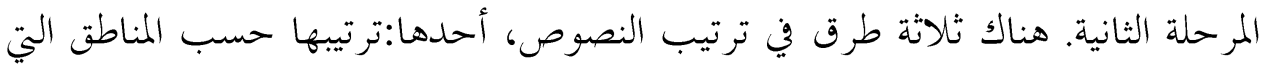
تتعلق فها النصوص وثانيها:ترتيبها باعتبار الموضوعات وثالثها:اعتبار عنصر الترتيب الزمني التاريخي هو الحكم. استفاد المؤلف من الطرق الثلاثة المذكورة حتي الإمكان. 
و النصوص المتعلقة بالموضوع بعينه جُمِعت بمقتضي الموضوع كالجزية والزكوة وغيرها.

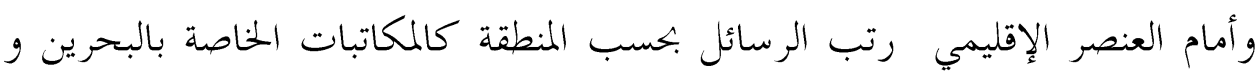
عمان. - n

أما النصوص الخاصة بصكو ك الأمان في الباب الخامس واختار المؤلف الطريقة الثانية

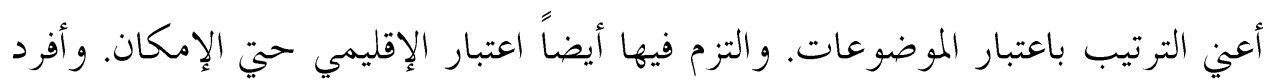

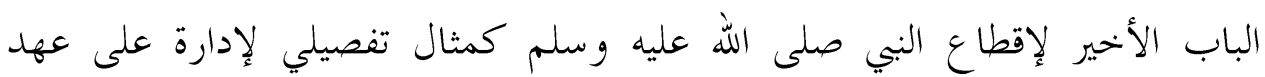
الرسول صلى الله عليه وسلم.

وفي الجملة قسم المؤلف هذه الدراسة إلى قسمين: القسم الأول خاصة بدراسة

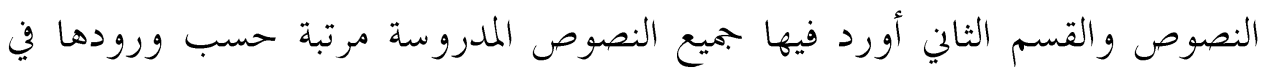

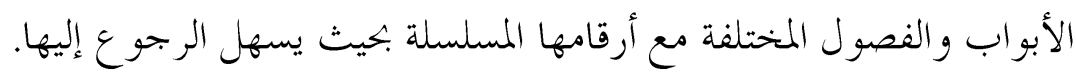

قد ركز المؤلف على دراسة كل نص على حدة وإثبات صحته قبل وضعه في

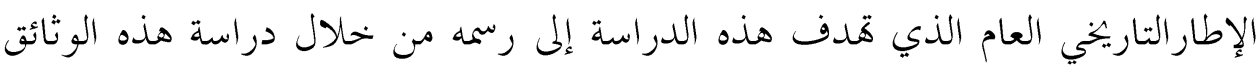
النبوية صلى الله عليه وسلم 26

$$
\text { نتائج البحث }
$$

( ) موضوع المكتوبات والمعاهدات من جانب موضوعُ السيرة ومن جانب آخر موضوعُ الحديث؛لأن ما صدر عن رسول اللّ صلى الله عليه وسلم من قول وفعل وتقرير فهوحديث. والمكتوبات و المعاهدات كُتبت بأمر البي صلى الله عليه وسلم فهي تتعلق بفعل الرسول صلى الله عليه وسلم.

${ }^{26}$ Aun al-Sharif Qasim al-Sudani, Nashat Ul Daula, Al Islamia, 1014. 
r) القو اعد للأخذ و القبول في فن السيرة والحديث مختلفة ولكن روايات السيرة مؤيدة

$$
\text { بالحديث فتوثق. }
$$

ب) بحوز الرواية بالمعني في السيرة فلذلك يو جد اختلاف الألفاظ في الروايات المختلفة في

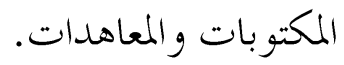

P ) هذه الدراسة عن التاليفات العربية الجديدة على معاهدات البي صلى الله عليه و سلم. والمحقق أن روايات المكتوبات و المعاهدات للبي صلى الله عليه وسلم مبعثرة في امهات الكتب في المصادر الأصلية. فجمع المؤلفون تلك الروايات على هذا الموضوع الخاص ودونوا تأليفاهم باللغة العربية.

ه) في العصر الحاضرمن أهم الكتب "رسالات نبوية عليه التحية" لمحمد عبدالمنعم خان وهومدارمهام للمؤلفين بعده فاتخذوه مأخذا ومصدرا. 9) "بحموعة الوثائق السياسية للعهد النبوي والخالافة الراشدة" للدكتور محمد حميدالله خزن واسع في هذا الباب. وبحث في ضوء المعاهدات عن الجهات الجديدة واستنبط منها المسائل والأحكام بطراز منفرد وذكر لكل رواية مصادر كثيرة حتي مصادر المستشرقين. "مكاتيب الرسول" لعلي بن حسين علي الأحمدي تأليف جيد ذكرفيه بو مكاتيب معصادركثيرة ووضح الكلمات الصعبة ومع بعدكل مكتوب عنوان بحث تاريخي، وذكر 
The Scholar Islamic Academic Research Journal

Vol. 6, No. 1 || Janurary -June2020||P.18-50

https://doi.org/10.29370/siarj/issue10ar7

فيه الأحوال السياسية التي في ذلك الزمن، وزاد المؤلف التشريحات المزيدة تحت عنوان

"التذنيب و التتميم" ولكن هناك قبائح موجودة لأفكار التشيع له و كتابه ملوث بمثالب

$$
\text { الصحابة الكرام رضي الله عنهم وطعنهم وتنقيصهم. }
$$

^) كتاب "نشأة الدولة الإسلامية" للدكتورعون الشريف قاسم بحموعة رائعة على موضوع المكاتيب، في هذا التأليف اختار المؤلف طرازاً منفرداً لدراسة النصوص الواردة المتعلقة بالمكاتيب والمعاهدات وبين الحقائق ومتعلقاها بالدلائل الخحمة أوّاًا وبعد ذلك ذكر النصوص من المصادر الأصلية الكثيرة المتنوعة كما ذكرنا الأمثلة تحت عنوان النقد.

\section{(C)(1)(8)}

BY NC SA This work is licensed under a Creative Commons Attribution-NonCommercial-ShareAlike 4.0 International (CC BY-NC-SA 4.0) 